\title{
Comprehensive tool for calculation of radiative fluxes: illustration of shortwave aerosol radiative effect sensitivities to the details in aerosol and underlying surface characteristics
}

\author{
Yevgeny Derimian $^{1}$, Oleg Dubovik ${ }^{1}$, Xin Huang ${ }^{1}$, Tatyana Lapyonok ${ }^{1}$, Pavel Litvinov ${ }^{1}$, Alex B. Kostinski ${ }^{2}$, \\ Philippe Dubuisson ${ }^{1}$, and Fabrice Ducos ${ }^{1}$ \\ ${ }^{1}$ Laboratoire d'Optique Atmosphérique, UMR8518 CNRS, Université de Lille, Villeneuve d'Ascq, 59655, France \\ ${ }^{2}$ Department of Physics, Michigan Technological University, 1400 Townsend Drive, Houghton, MI 49931, USA
}

Correspondence to: Yevgeny Derimian (yevgeny.derimian@univ-lille1.fr)

Received: 14 October 2015 - Published in Atmos. Chem. Phys. Discuss.: 26 November 2015

Revised: 17 March 2016 - Accepted: 17 April 2016 - Published: 11 May 2016

\begin{abstract}
The evaluation of aerosol radiative effect on broadband hemispherical solar flux is often performed using simplified spectral and directional scattering characteristics of atmospheric aerosol and underlying surface reflectance. In this study we present a rigorous yet fast computational tool that accurately accounts for detailed variability of both spectral and angular scattering properties of aerosol and surface reflectance in calculation of direct aerosol radiative effect. The tool is developed as part of the GRASP (Generalized Retrieval of Aerosol and Surface Properties) project. We use the tool to evaluate instantaneous and daily average radiative efficiencies (radiative effect per unit aerosol optical thickness) of several key atmospheric aerosol models over different surface types. We then examine the differences due to neglect of surface reflectance anisotropy, nonsphericity of aerosol particle shape and accounting only for aerosol angular scattering asymmetry instead of using full phase function. For example, it is shown that neglecting aerosol particle nonsphericity causes mainly overestimation of the aerosol cooling effect and that magnitude of this overestimate changes significantly as a function of solar zenith angle (SZA) if the asymmetry parameter is used instead of detailed phase function. It was also found that the nonspherical-spherical differences in the calculated aerosol radiative effect are not modified significantly if detailed BRDF (bidirectional reflectance distribution function) is used instead of Lambertian approximation of surface reflectance. Additionally, calculations show that usage of only angular scattering asymmetry, even for the case of spherical aerosols, modifies the dependence of in-
\end{abstract}

stantaneous aerosol radiative effect on SZA. This effect can be canceled for daily average values, but only if sun reaches the zenith; otherwise a systematic bias remains. Since the daily average radiative effect is obtained by integration over a range of SZAs, the errors vary with latitude and season. In summary, the present analysis showed that use of simplified assumptions causes systematic biases, rather than random uncertainties, in calculation of both instantaneous and daily average aerosol radiative effect. Finally, we illustrate application of the rigorous aerosol radiative effect calculations performed as part of GRASP aerosol retrieval from real POLDER/PARASOL satellite observations.

\section{Introduction}

Direct atmospheric aerosol radiative forcing remains one of the most uncertain components in evaluation of Earth's climate change (Andreae et al., 2005; Hansen et al., 2011). Although aerosols are generally recognized as having a negative radiative effect (cooling) on the surface-atmosphere system, in some conditions aerosol can also have a positive radiative effect (warming). The aerosol cooling effect is produced by reflecting solar radiation back to space, i.e., scattering in the upward direction. Depending on their composition, aerosol can also heat due to absorption of the incoming solar radiation. However, not only properties of aerosol but also of the undelaying surface are decisive for the sign of the aerosol radiative effect. For example, the same particles can de- 
crease (warming effect) or increase (cooling effect) the planetary albedo depending on whether the underlying surface is a bright desert or dark ocean. Regardless of warming or cooling from the point of view of top-of-atmosphere albedo, aerosols always warm the atmospheric layer if their absorption is not 0 . In addition, the aerosols generate a heating effect in thermal infrared spectrum, primary caused by large mineral dust particles that strongly absorb outgoing terrestrial radiation (e.g., Legrand et al., 2001). This aerosol heating effect in thermal infrared spectrum is similar to the effect of greenhouse gasses and thus counteracts the aerosol scattering effect in the solar spectrum. For clarity of the analysis performed in this study it is important to recall that the term aerosol direct radiative forcing, which is defined as perturbation of radiative fluxes due to human-induced components only, is therefore different from the term radiative effect. Aerosol radiative effect refers to the difference between radiative fluxes in aerosol-free and aerosol-laden atmospheric conditions (e.g., Kaufman et al., 2005; Remer and Kaufman, 2006). Using measurements, one can assess the aerosol radiative effect by referring to aerosol-free conditions. In climate models, however, it is feasible to evaluate forcing by referring to background or pre-industrial aerosol. Therefore, because of the possibility to control numerous aerosol emission and transport processes, evaluation of radiative forcing of climate relies mostly on chemical transport and general circulation models. In order to reduce dependence on assumptions that take place in the models, important steps towards evaluation of aerosol direct radiative effect are also taken using global aerosol and broadband flux observations from satellite and ground-based remote sensing (Boucher and Tanré, 2000; Yu et al., 2004; Bellouin et al., 2005; Zhou et al., 2005; Remer and Kaufman, 2006; Yu et al., 2006; Su et al., 2013). The observation-based evaluations of aerosol radiative effect create opportunities for intercomparison with models and lead to improvement in the assessment of aerosol radiative effect on climate. Therefore, there is an interest in continuing the measurement-based evaluation of the aerosol radiative effect and examination of possible sources of uncertainty. For example, descriptions of angular and spectral features of scattering properties of aerosol and underling surface are often simplified. The reasons for using these simplifications are usually the lack of information regarding the details of these properties and the need for substantial reduction of the computation time required for rigorous flux computations. For instance, accurate modeling of scattering by nonspherical particles and directional reflectance of surface is challenging and therefore often neglected. Recent advancements in retrievals of aerosol optical characteristics from ground and space remote sensing and from a combination of sensors show capabilities to provide more detailed properties. For example, aerosol size distribution, complex refractive index, single scattering albedo and nonspherical fraction become available not only from ground-based photometric observations (Dubovik et al., 2002b, 2006) but also from space sensors (Dubovik et al., 2011, 2014), providing the advantage of large spatial coverage. The retrievals from space also provide information about the surface spectral albedo or bidirectional reflectance distribution function (BRDF) parameters. In addition, the aerosol layer height can be retrieved using even passive polarimetric sensors (Dubovik et al., 2011; Tanré et al., 2011), while a combination of passive and active sensors shows sensitivity to vertical profiles of extinction by aerosol in fine and coarse mode fractions (Lopatin et al., 2013). These upcoming enhanced remote sensing retrievals imply the possibility of more accurate aerosol radiative effect computation that largely relies on the measurements and reduced level of assumptions. For example, a close agreement is found in an intercomparison of measured downward solar flux at the surface with fluxes computed as part of the AERONET product. The studies conducted in the framework of a field campaign (Derimian et al., 2008), on a global scale (García et al., 2008) and in specific case studies (Derimian et al., 2012) show that the computed broadband solar flux generally agrees with the measured flux to within 5 to $10 \%$; note that accuracy of solar flux measurements themselves is on the order of $5 \%$. The agreement between simulated and measured flux is remarkable yet to be expected if the computational approach employed here is understood. The main advantage of the approach is that the retrieved aerosol and surface properties should fit the measured radiances at given wavelengths within a few percent, as it requires the inversion algorithm. Obviously, an interpolation or extrapolation outside of the nominal wavelengths is needed and the errors may accumulate during spectral radiances calculations and after radiances integration into broadband flux. Essentially, it also implies that the retrieved aerosol models that satisfy fit of simulated to measured radiances in inversion algorithms should also accurately reproduce the spectral variability of aerosol properties in the simulation of broadband flux. Accurate and high spectral resolution computations of radiances that account for spectral variability of gaseous absorption and detailed aerosol characteristics, such as detailed phase function, which strongly depend on particle sizes, shapes and index of refraction, should increase the accuracy of the simulated flux. For example, the importance of accounting for particle nonsphericity in calculation of desert dust radiative forcing is addressed in several discussions (Mishchenko et al., 1995; Bellouin et al., 2004; Kahnert and Kylling, 2004; Kahnert et al., 2005; Derimian et al., 2008; Yi et al., 2011). Indeed, nonsphericity of the particles shape is often neglected in aerosol radiative effect computations, mainly due to necessity to reduce computational time. Hence, an assumption is made that the differences in angular scattering by spherical and nonspherical particles are canceled when all contributions of scattered light are summed up into the total hemispherical flux. Also, the computation approach generally implies usage of the asymmetry parameter, which is an integrated value, and therefore differences in the aerosol phase function of spheres and spheroids are expected be averaged 
out. However, Kahnert and Kylling (2004) and Kahnert et al. (2005) conducted a detailed analysis of asymmetry parameter sensitivity to particle shape and concluded that the use of spherical particles model might be among the major error sources in broadband flux simulations. In the work by Derimian et al. (2008) the effect of particles nonsphericity on forcing was evaluated using detailed phase function in the flux calculations. The nonsphericity effect was evaluated for cases of dust and mixed aerosol type during biomass burning season in western Africa. The computations revealed that neglecting particles' nonsphericity leads to a systematic overestimation of the aerosol cooling effect by up to $10 \%$; the bias was pronounced in instantaneous and daily average values. It was also noted that the magnitude of the overestimation depends on the magnitude of aerosol absorption and aerosol optical thickness (AOT or $\tau$ ). Later general sensitivity tests by Yi et al. (2011) evaluated the errors in radiances and flux due to spherical particles approximation, which resulted in conclusions consistent with effects observed by Derimian et al. (2008) in the specific case study. We would like to emphasize here that features of aerosol directional scattering are also important for accurate modeling of diurnal dependence of forcing, i.e., dependence of aerosol instantaneous forcing on the solar zenith angle (SZA). This SZA dependence of aerosol radiative effect at the top of atmosphere (TOA) appeared in an earlier simple expression developed for calculations of Earth-atmosphere albedo perturbation (Lenoble et al., 1982). Later it was confirmed by exact radiative transfer computations (e.g., Bellouin et al., 2004), taken into account in space instrument forcing studies using POLDER (Boucher and Tanré, 2000) and MODIS (Remer and Kaufman, 2006) and using AERONET retrievals (e.g., Derimian et al., 2008, 2012; García et al., 2012). It is also worth mentioning that the diurnal dependence of forcing is influenced by directional properties of the underlying surface. The effect was discussed by Yu et al. (2004) for land and by Bellouin et al. (2004) for ocean using the BRDF.

In the current study we introduce a rigorous computational tool for broadband flux simulations and demonstrate the importance of detailed representation of aerosol and surface. We apply our simulation for (i) evaluating radiative effect of several key aerosol models; then (ii) we stress importance of diurnal dependence (dependence on SZA) of the aerosol radiative effect and (iii) examine the effects of assumptions using simplified representations of aerosol phase function, particle shape and directional properties of surface reflectance. It is often expected that the details of aerosol and surface optical properties are not really important because the flux is an integral product of spectral and angular properties of atmospheric radiation. Therefore we intend to clarify whether any cancelations of uncertainties appear in the integrated broadband hemispherical flux due to coexisting assumptions on aerosol and surface directional scattering.

Thus, the below paper is organized as follows. Section 2 provides a description of the flux computational tool. Sec- tion 3 contains a description of aerosol models used in the sensitivity tests. In Sects. 4 and 5 we analyze the importance of the diurnal dependence of the instantaneous aerosol radiative effect, which also varies as a function of aerosol characteristics and the surface albedo model. Section 6 provides the discussion about complexity of evaluation of the nonspherical-spherical difference in aerosol radiative effect due to a concurrent change in directional redistribution of scattering and spectral extinction cross sections of volumeequivalent spheres and spheroids. Section 7 discusses the errors appearing in radiative effect calculations due to the use of a simplified representation of aerosol directional scattering by asymmetry parameter. Finally, Sect. 8 includes an example of aerosol radiative effect computation for a part of Africa using the GRASP (Generalized Retrieval of Aerosol and Surface Properties) algorithm (Dubovik et al., 2014) applied to POLDER/PARASOL observations.

\section{Computational code description}

The initial version of this broadband solar flux computational tool was originally built in the AERONET operational code (Dubovik and King, 2000); the performances were studied and intercomparisons with the ground-based flux measurements conducted on a global scale (García et al., 2008) and in specific case studies (Derimian et al., 2008). As described below, the tool is significantly revised and integrated into the GRASP unified algorithm for characterizing atmosphere and surface. Thus, at present, the calculations can be performed as part of measurements processing and the radiative effect estimations can be provided in the framework of GRASP retrieval product. It is also possible to use the computational tool in various types of independent research calculations.

Computations of broadband solar flux in spectral interval from 0.2 to $4.0 \mu \mathrm{m}$ and of aerosol radiative effect are based on forward modeling of atmospheric radiances and flux simulations employed in the GRASP algorithm which inherits aerosol representation from AERONET retrieval code (Dubovik and King, 2000; Dubovik et al., 2006; Sinyuk et al., 2007). Figure 1 shows a general structure of the aerosol radiative effect simulation logistic. The input includes ozone and water vapor concentrations and a set of "retrieved parameters" (see Dubovik et al., 2011, 2014) that includes aerosol volume size distribution, real and imaginary part of spectral complex refractive index, fractions of spherical particles, parameters of aerosol vertical distribution and parameters of BRDF surface reflectance. It also includes information about maximal sun elevation and daylight duration that is required for evaluation of $24 \mathrm{~h}$ average radiative effect. It should be noted that in the presented studies the vertical distribution of aerosol extinction was fixed and assumed as a Gaussian distribution with maxima at an altitude of $1 \mathrm{~km}$ and standard deviation of 0.7 . However, if a realistic aerosol vertical profile is available, it can be included as part of the in- 
put and used in the calculations. For example, GRASP retrievals provide aerosol medium height from PARASOL observations (Dubovik et al., 2011) and GaRRliC/GRASP retrieval provides detailed vertical profiles from joint inversion of ground-based photometer and lidar data (Lopatin et al., 2013). The gaseous content in the atmospheric column is assessed from a combination of retrievals, climatology values and standard atmospheric models. In the presented computations, for instance, instantaneous water vapor content is retrieved by AERONET using the absorption differential method at the $0.94 \mu \mathrm{m}$ channel (Smirnov et al., 2000), the total ozone content is obtained from the monthly climatology values of NASA Total Ozone Mapping Spectrometer (TOMS) and US standard 1976 atmosphere model is used for other gases and atmospheric gaseous profiles. The aerosol optical characteristics calculated at 208 spectral intervals, gaseous absorption $k$ distribution and surface reflectance (Lambertian or BRDF based) are then supplied into atmospheric radiative transfer calculations. The aerosol optical thickness, single scattering albedo $\left(\omega_{0}\right)$ and phase function $(P(\Theta))$ (or phase matrix) are calculated for each of the 208 spectral intervals using the size distribution, complex refractive index and fraction of spherical particles. The missing spectral values of the complex refractive index are linearly interpolated or extrapolated from the values provided in the input since spectral behaviors of aerosol complex refractive index in the solar spectrum are sufficiently smooth. The details of the aerosol phase function are taken into account using a 12-moment expansion of the Legendre polynomial; however, usage of asymmetry parameter only (first moment expansion of the Legendre polynomial) is also possible. The aerosol single scattering properties are modeled using precomputed kernel look-up tables produced for a set of size parameters, complex refractive indices and fraction of spherical particles. The fixed aspect ratio distribution of prolate/oblate spheroids, used for the nonspherical aerosol component, is derived (Dubovik et al., 2006) as a best fit of detailed phase matrices measured in the laboratory by Volten et al. (2001). This approach enables us to conduct the flux simulations in a reasonable computational time even when a nonspherical aerosol model and detailed representation of spectral aerosol phase function are taken into account. The effects of multiple scattering in broadband integration are accounted for using accurate radiative transfer calculations by vector successive order of scattering code (Lenoble et al., 2007) modified by adding several flexibilities desirable for aerosol retrievals (see Dubovik et al., 2011). It should be noted that the initial version of flux calculations used in the AERONET code employs the discrete ordinates radiative transfer code (DISORT) (Nakajima and Tanaka, 1988; Stamnes et al., 1988). The gaseous absorption $\left(\mathrm{H}_{2} \mathrm{O}, \mathrm{CO}_{2}\right.$ and $\left.\mathrm{O}_{3}\right)$ is accounted for using the same approach as the one adapted in a module of the radiative transfer model GAME (Global Atmospheric ModEl) (Dubuisson et al., 1996, 2006; Roger et al., 2006). Specifically, gaseous absorption is calculated by utilizing the

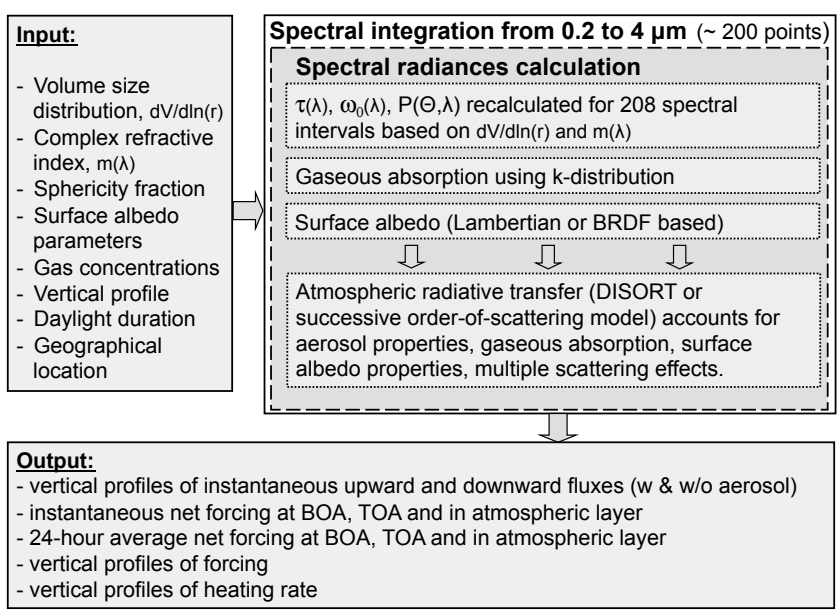

Figure 1. General organization structure of computational code for broadband solar flux and aerosol radiative effect computations.

correlated $k$ distribution (Lacis and Oinas, 1991) that allows broadband flux simulations with acceptably short computational time. The coefficients of the correlated $k$ distribution have been estimated from reference calculations using a lineby-line code (Dubuisson et al., 2004). Modeling of the surface reflectance is done either by BRDF model (using various models as described by Dubovik et al., 2011) or using Lambertian approximation. In current sensitivity tests we used the Li-Ross BRDF model for calculation of the land surface reflectance (Roujean et al., 1992; Rahman et al., 1993; Wanner et al., 1995). The surface spectral reflectance was modeled using climatological values provided by MODIS, and the missing spectral values are linearly interpolated or extrapolated, in a manner similar to the complex refractive index. Thus, spectral variability of aerosol optical characteristics, gaseous absorption, molecular scattering and surface albedo is carefully taken into account in the computation of spectral radiances that afterwards are integrated into the broadband solar flux.

As mentioned above, several important revisions of the radiative effect computation tool were done as part of GRASP project advancement (Dubovik et al., 2011). The significant reduction of computational time of spectral radiances was one of these advancements. Another advantage, compared to the original tool, is that the radiative transfer code implemented in the GRASP also accounts for polarization and can account for both aerosol phase matrix and surface BPDF (bidirectional polarization distribution function). Note that in the presented sensitivity calculation the polarization effects were not considered, but they are accounted for in application for POLDER/PARASOL observations. Finally, the most important advancement is that all the aerosol and surface properties that are necessary for the broadband solar flux calculation can be derived simultaneously by GRASP as retrieval products, e.g., using POLDER/PARASOL obser- 
vations. In addition, there is an interest in interpreting new aerosol retrievals produced by GRASP on the level of direct aerosol radiative effect. The radiative effect calculation strategy described above is therefore driven by this motivation and is tied to the retrieved characteristics provided by GRASP. Spectral dependent properties, such as aerosol complex refractive index, BRDF and BPDF parameters derived only at the fixed instrumental channels, are used after interpolation or extrapolation in the same manner as was done in initial version of the computational tool. The gas absorptions calculations using the correlated $k$-distribution method are adapted for convenience of satellite measurement processing. For example, in order to circumvent the time-consuming convolutions among all the gas species, only the water vapor and ozone contents are set to the real-time values obtained from satellite retrievals (e.g., POLDER, TOMS). The other gases, whose concentration ratios to the carbon dioxide vary little among different atmospheric profiles, are considered as one mixed gas based on their concentration ratios in the US standard 1976 atmosphere model (the $\mathrm{CO}_{2}$ concentration was updated to a more recent one).

The results of calculations include instantaneous upward and downward fluxes (with and without aerosol), instantaneous net radiative effect at the bottom of atmosphere (BOA), TOA and in the atmospheric layer, $24 \mathrm{~h}$ average net radiative effects (BOA, TOA and atmospheric layer) and vertical profiles of aerosol radiative effect for a given aerosol profile. The aerosol net radiative effect is defined as the difference between downwelling and upwelling fluxes at a given atmospheric layer in aerosol-free and aerosol-laden conditions; that is, at the BOA the net radiative effect is defined as

$$
\Delta F_{\mathrm{BOA}}^{\mathrm{Net}}=\left(F_{\downarrow \mathrm{BOA}}^{a}-F_{\uparrow \mathrm{BOA}}^{a}\right)-\left(F_{\downarrow \mathrm{BOA}}^{0}-F_{\uparrow \mathrm{BOA}}^{0}\right),
$$

where $F_{\downarrow \mathrm{BOA}}^{a}$ and $F_{\uparrow \mathrm{BOA}}^{a}$ are downwelling and upwelling fluxes in aerosol-laden conditions and $F_{\downarrow \mathrm{BOA}}^{0}$ and $F_{\uparrow \mathrm{BOA}}^{0}$ are downwelling and upwelling fluxes in aerosol-free conditions. The aerosol radiative effect at the TOA is defined similarly and can be written as follows:

$$
\begin{aligned}
\Delta F_{\mathrm{TOA}}^{\mathrm{Net}} & =\left(F_{\downarrow \mathrm{TOA}}^{a}-F_{\uparrow \mathrm{TOA}}^{a}\right)-\left(F_{\downarrow \mathrm{TOA}}^{0}-F_{\uparrow \mathrm{TOA}}^{0}\right) \\
& =F_{\uparrow \mathrm{TOA}}^{0}-F_{\uparrow \mathrm{TOA}}^{a},
\end{aligned}
$$

because at the TOA the downwelling (extraterrestrial) flux is the same for either aerosol-free or aerosol-laden conditions. The difference between the net TOA and net BOA radiative effects is the atmospheric radiative effect (ATM) that represents the energy trapped in the atmosphere due to the aerosol presence:

$$
\Delta F_{\mathrm{ATM}}^{\mathrm{Net}}=F_{\mathrm{TOA}}^{\mathrm{Net}}-F_{\mathrm{BOA}}^{\mathrm{Net}} .
$$

The $24 \mathrm{~h}$ average aerosol radiative effect is computed by integration of instantaneous values up to minimal SZA of a given day of the year and at given latitude. These instantaneous values are calculated with a half-degree SZA resolution or Gaussian quadrature in the GRASP version. Knowing the daylight duration and minimal SZA of that day, the SZA interval is converted into a corresponding time interval by which the instantaneous values are integrated over the time of the daylight duration. The obtained integral represents energy perturbed by aerosols during the daylight time. This value is then divided by $24 \mathrm{~h}$ to get the perturbation per day - the daily average radiative effect.

\section{Aerosol models}

Several key aerosol models are selected in order to evaluate their radiative effect under different assumptions. The average aerosol models are derived from all available years of AERONET observations and include dust and mixture of dust with biomass burning aerosol in the Dakar site (also known as Mbour), biomass burning aerosol in the Mongu site, urban/industrial pollution in the Paris site and mixture of dust with urban/industrial aerosol in the Kanpur site. Except for Dakar, the AERONET sites and aerosol models are selected pursuing the works of Dubovik et al. (2002a) and Giles et al. (2012). The Dakar site was studied in the framework of the AMMA campaign (Haywood et al., 2008) and is characterized by a mixture of dust with biomass burning aerosol during the dry season in January and February and by desert dust only starting from March (e.g., Derimian et al., 2008; Léon et al., 2009). The aerosol characteristics are derived using version 2, level 2 almucantar AERONET product and applying criteria recommended in Dubovik et al. (2002a). Additionally, a seasonal criterion is applied for the Mongu site in southern Africa, where the biomass burning aerosol model is derived during the summer period that is known as a peak of the biomass burning season. It has to be mentioned that at this site the aerosol absorption was found as varying within the biomass burning season (Eck et al., 2013); thus variability in the biomass burning radiative efficiency is also expected. For the purpose of our study, however, we take only an averaged characteristic and select August and September as the months with highest aerosol optical thickness and maximal number of observations. An additional criterion that was used to distinguish the aerosol type is the value of Angström exponent ( $(\stackrel{a}{)})$ between wavelengths of 870 and $440 \mathrm{~nm}$. The Ångström exponent below 0.6 is attributed to dust, between 0.8 and 1.2 to a mixed aerosol type in Dakar and Kanpur sites, above 1.6 for urban/industrial pollution in Paris and above 1.6 for the biomass burning in the Mongu site. Average fractions of spherical particles obtained for these aerosol types were also examined. The values logically correspond to the defined aerosol models: $3 \%$ for dust in Dakar, $5 \%$ for mixture of dust and biomass burning in Dakar, $21 \%$ for mixture of dust and urban/industrial in Kanpur, $98 \%$ for urban/industrial in Paris and $99 \%$ for biomass burning in 
Table 1. Complex refractive index for the employed aerosol models.

\begin{tabular}{lrr}
\hline Aerosol model & \multicolumn{2}{c}{ Complex refractive index } \\
\cline { 2 - 3 } & $n$ & $k(440 / 670 / 870 / 1020)$ \\
\hline Dust (Dakar, Senegal) & 1.47 & $0.004 / 0.002 / 0.002 / 0.002$ \\
Biomass Burning (Mongu, Zambia) & 1.51 & 0.023 \\
Urban (Paris, France) & 1.39 & 0.007 \\
Mixture of dust and BB (Dakar, Senegal) & 1.45 & $0.021 / 0.016 / 0.013 / 0.013$ \\
Mixture of dust and urban (Kanpur, India) & 1.50 & $0.013 / 0.010 / 0.009 / 0.009$ \\
\hline
\end{tabular}

Mongu. These values were also employed in calculations of aerosol radiative effect presented in this study. Other details of the selected aerosol models are presented in Table 1 and Fig. 2. In order to facilitate a straightforward intercomparison of relative importance of fine and coarse modes of different aerosol models, the volume size distributions in Fig. 2a are normalized by total volume concentrations, i.e., their integration over radii is equal to unity. Spectral dependences of aerosol optical thicknesses are normalized by their maximal values and are intercomparable in Fig. $2 b$; the related values of $\stackrel{a}{a}(870 / 440 \mathrm{~nm})$ are also presented in the figure. Based on the derived size distributions and complex refractive index, the spectral $\omega_{0}$ and asymmetry parameter $(g)$ are calculated over the entire range of the solar spectrum; to that end the complex refractive index is linearly interpolated between the nominal wavelengths and is fixed to the last value beyond them (see Table 1).

Note that the computed $g$ and $\omega_{0}$ have quite strong spectral variability (Fig. 2c, d), which illustrates strong dependence of $g$ and also of $\omega_{0}$ on the ratio of particles size to wavelength. For example, in the cases of biomass burning and urban aerosol models, the $\omega_{0}(\lambda)$ is changing even if imaginary part of refractive index is spectrally constant (see Table 1 and Fig. 2c). After having a maximum at short wavelengths, the $\omega_{0}(\lambda)$ increases again at longer wavelengths for all aerosol models where the bimodal size distribution is strongly pronounced (i.e., except for dust). This is due to increasing scattering effectiveness of fine and coarse modes at short and long wavelengths, respectively. The scattering effectiveness in case of dust aerosol model is increasing only at long wavelengths. The spectral dependence of $g(\lambda)$ is also noteworthy. For aerosol models with significant fine mode, it could be expected that with the decrease of the particle size relative to wavelength, the asymmetry parameter will monotonously decrease. However, $g$ starts to increase (increase of scattering in forward hemisphere) at long wavelengths for all aerosol models, apparently due to the bimodality of the size distributions and increasing contribution of the coarse mode.

A pronounced spectral dependence in the directional scattering can also be seen in Fig. 3, which shows $P 11(\theta) \times$ AOT $_{\text {scat }}$, where $P 11(\theta)$ is the phase function that fulfills the following normalization condition:
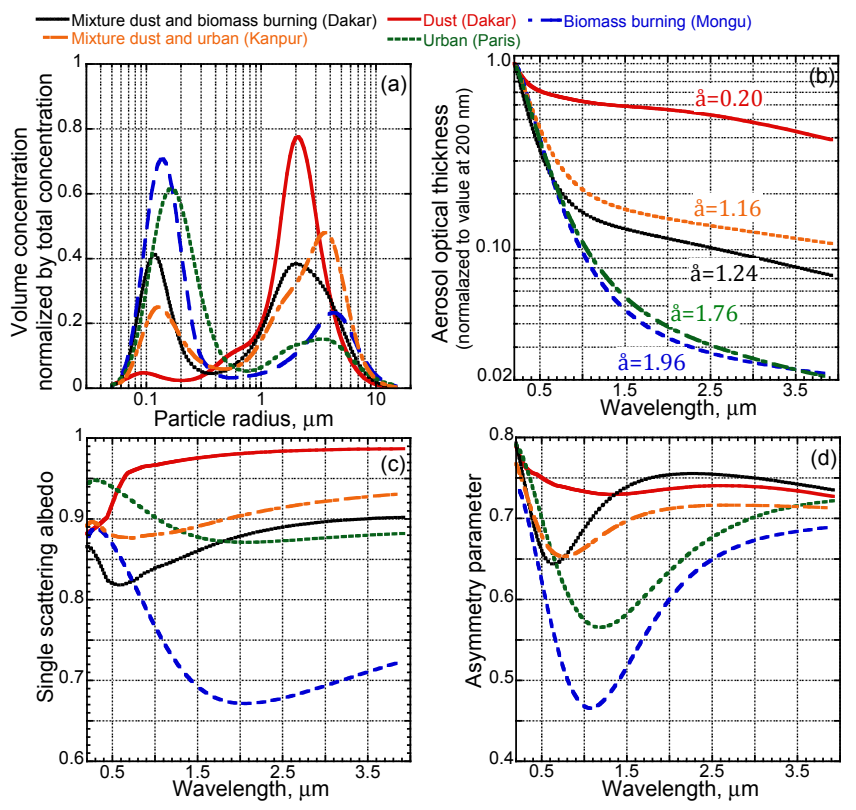

Figure 2. Characteristics of the employed aerosol models: (a) volume size distributions are normalized by total volume concentration; (b) spectral aerosol optical thickness normalized by maxima at $200 \mathrm{~nm}$; (c) spectral single scattering albedo; (d) spectral asymmetry parameter.

$\frac{1}{2} \int_{0}^{\pi} P 11(\theta) \times \sin \theta \mathrm{d} \theta=1$.

Therefore, the presented examples of significant spectral variability of $\omega_{0}, g$ and directional scattering emphasize the importance of accurate accounting for the aerosol spectral characteristics in the broadband flux simulations. However, it is fair to say that the solar constant is rapidly decreasing outside of the visible interval, which partially diminishes inaccuracy in aerosol spectral characteristics. Another curious observation can be made regarding the single scattering albedo of the mixed aerosol type. In both cases of mixture (dust with biomass burning and dust with urban/industrial pollution) the single scattering albedo is lower than that estimated using a simple additive combination of each compo- 


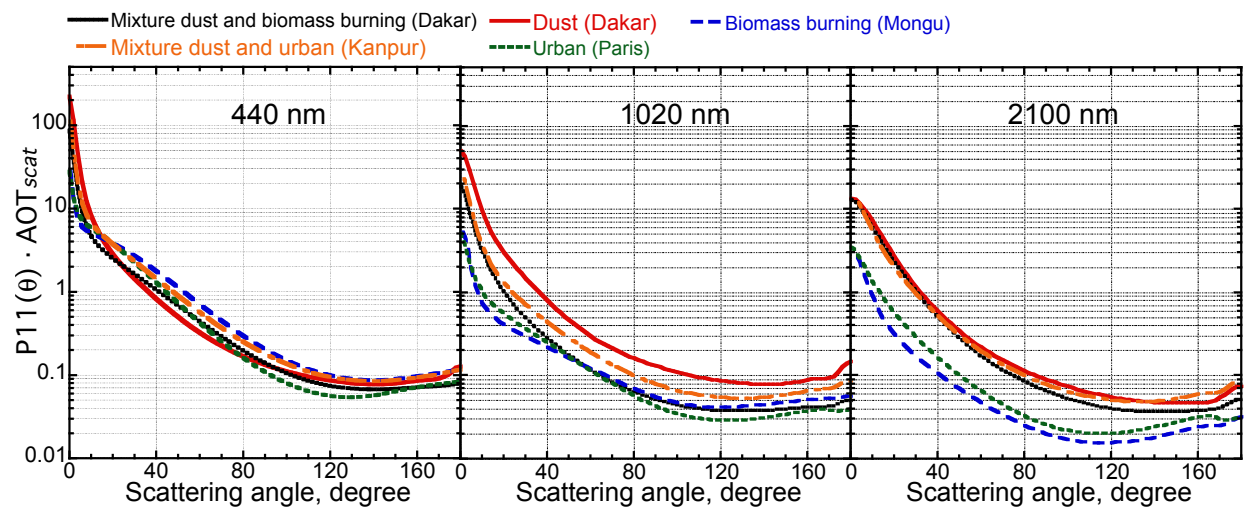

Figure 3. The calculated directional scattering of the employed aerosol models at 440, 1020 and $2100 \mathrm{~nm}$.

nent. A simple additive combination of single scattering albedos is valid for aerosol external mixture case, though it apparently can hardly explain the low single scattering albedo values observed for the mixed aerosol type other than by the presence of excessive absorption of pollution in Kanpur and of smoke in Dakar. The existence of internal mixture of different chemical elements (e.g., presence of absorbing material on the surface of coarse mode particles) is another explanation of that decrease the scattering effectiveness.

\section{Diurnal dependence of instantaneous forcing}

Strong dependence of instantaneous aerosol radiative effect on SZA implies importance of (i) the proper intercomparison of instantaneous values assessed in different time and location and (ii) the evaluation of the daily average radiative effect, which is obtained by integration over corresponding range of SZAs in a given day and location. In order to examine dependence on SZA, diurnal radiative efficiencies are calculated for the above-presented aerosol models. The radiative efficiencies are calculated with respect to AOT at $550 \mathrm{~nm}$ and over Lambertian ocean surface albedo. The aerosol radiative efficiency is used in order to examine influence of different aerosol type and not of concentration, which is supposed to be ruled out because efficiency is defined as radiative effect per unit AOT. One should remember, however, that the aerosol radiative effect is not a linear function of AOT, e.g., as discussed by Markowicz et al. (2008). Thus, for a consistent intercomparison of radiative efficiencies calculated for different aerosol models, we choose to set all corresponding AOTs at $550 \mathrm{~nm}$ to unit.

The first observation that can be drawn from the Fig. 4 is that not only magnitude but also the shape of the curves of radiative efficiency vs. $\cos (\mathrm{SZA})$ depends on the aerosol type. Note that $\cos (\mathrm{SZA})$ is used hereafter since this variable appears in the radiative transfer equation. This shape is essentially linked to the differences in aerosol phase functions. Significant dependence of the instantaneous radiative effect

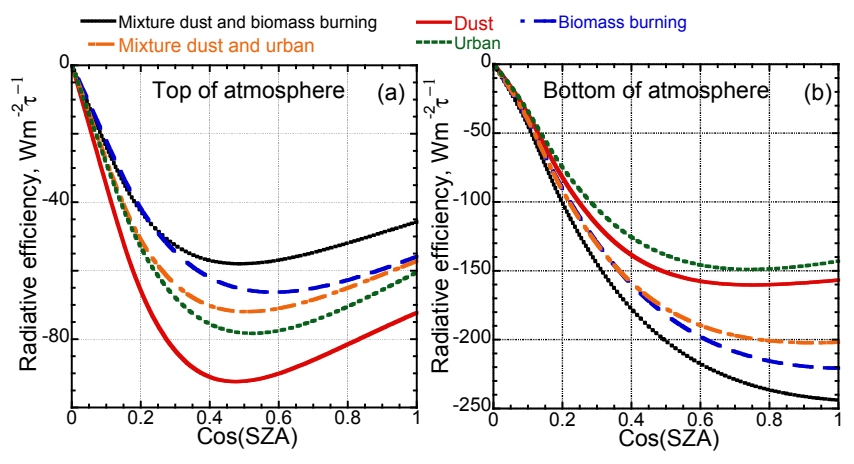

Figure 4. Instantaneous aerosol radiative efficiencies with respect to $550 \mathrm{~nm}$ at the (a) top of atmosphere and (b) bottom of atmosphere calculated over ocean Lambertian surface reflectance.

on SZA also implies that its accurate computation is important for the daily average radiative effect. Hence, a proper analysis and intercomparison of not only instantaneous but also of the daily average aerosol forcings should respect the range of SZAs. Consistency in the daylight time duration should also be taking into account if one intends to attribute the differences in the daily average radiative effect to differences in aerosol type or concentration. Strictly speaking, the same aerosol type and concentration over the same surface and in same location, but at different times of the year or on the same day but in different latitudes, will give different value of daily average forcing. Otherwise, for a consistent intercomparison, a standard can be assumed; for example, the sun reaches the zenith $\left(\mathrm{SZA}=0^{\circ}\right)$ and the daylight fraction is 0.5 (daylight duration is $12 \mathrm{~h}$ ). Coming back to the Fig. 4 , a difference can also be noted in angular dependence of aerosol radiative effect at TOA and BOA. At TOA the negative radiative effect starts to decrease for higher sun elevation, but at BOA it continues to increase or stays more or less constant (depending on the aerosol model). Remembering that the difference between TOA and BOA forcings is the atmospheric forcing, this means that efficiency of atmospheric layer heat- 
ing due to the aerosol presence is increasing for increasing sun elevation.

\section{Directional properties of surface reflectance}

It is known that the aerosol radiative impact on the Earth's albedo depends not only on the aerosol properties but also on reflectance of the underlying surface. In general, to describe surface reflectance accurately, the BRDF is required. The BRDF depends on illumination and scattering geometries (e.g., Litvinov et al., 2011, 2012). Therefore, diurnal dependence of aerosol radiative effect is also expected to vary with respect to SZA and directional properties of the surface reflectance. As a first approximation of surface reflectance description such characteristic as "black-sky" albedo (also known as directional hemispherical reflection, DHR) is often used. It can be defined through the integrals of BRDF (Schaepman-Strub et al., 2006):

$\operatorname{DHR}\left(\lambda, \vartheta_{0}\right)=\int_{0}^{2 \pi} \int_{0}^{\frac{\pi}{2}} \operatorname{BRDF}\left(\lambda, \vartheta_{0}, \vartheta_{v} \varphi\right) \cos \vartheta_{v} \sin \vartheta_{v} \mathrm{~d} \vartheta_{v} \mathrm{~d} \varphi$,

where $\vartheta_{v}$ and $\vartheta_{0}$ are reflected and solar zenith angles, $\varphi$ is the difference of azimuth angles of reflected and solar directions and $\lambda$ is the wavelength of incident radiation.

Figure 5a shows an example of surface black-sky albedo dependence on SZA at three AERONET sites employed in this study. These surface albedos are obtained for Ross-Li BRDF model, where the BRDF parameters are derived from MODIS climatology. As can be seen, the BRDF-based surface albedos significantly deviate from an isotropic Lambertian surface albedo that has no dependence on SZA. Stronger directional dependence for the desert sites than for a site in southern Africa can be also noted, which is consistent with a known general feature of soil vs. vegetation surfaces (e.g., Maignan et al., 2004; Litvinov et al., 2011, 2012). In Fig. 5b we show dependence on SZA of Lambertian to BRDF-based albedo ratio for three wavelengths over the solar spectrum. The ratio is equal to unity when the Lambertian albedo is equal to the BRDF-based albedo; thus it shows that underestimation (ratio below unity) or overestimation (ratio above unity) of the surface reflectance due to simplified Lambertian model is a function of SZA and wavelength. It therefore emphasizes the importance of the assumption on the surface albedo model of the diurnal dependence and absolute values of the aerosol radiative effect. However, if we consider the whole range of SZAs, the effect on the daily average aerosol effect can be partially canceled because the values below and above unity can be quasi-symmetric. For instance, for the monthly average TOA aerosol direct radiative effect over global land derived from MODIS, Yu et al. (2004) found an uncertainty due to neglecting of the angular dependence of the albedo of only about $5 \%$. However, the influence of the directional properties of the surface albedo is expected to
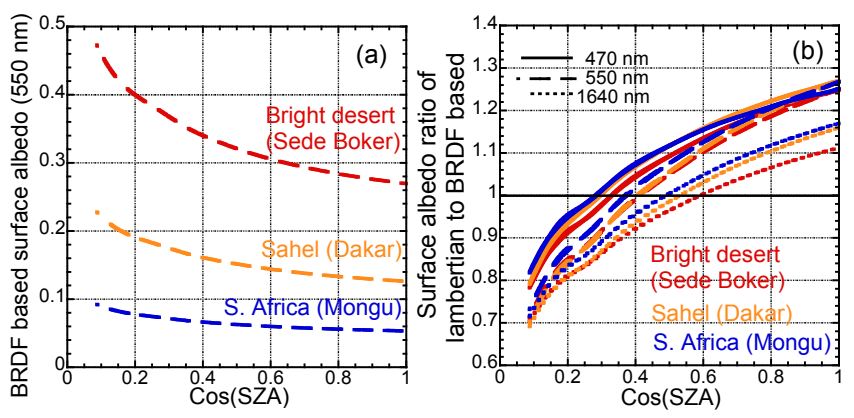

Figure 5. (a) Dependence of the BRDF-based surface "black-sky" albedo (here presented at $550 \mathrm{~nm}$ ) on solar zenith angle for thee different surface types. (b) Ratio of Lambertian surface model to BRDF-based surface model black-sky albedos at three different wavelengths and for three surface types.

vary depending on the range of SZAs over which the integration is done in order to obtain the daily average forcing. We therefore draw attention to the fact that the magnitude of the uncertainty will be a function of latitude and day of the year. Asymmetry of the ratio around unity in Fig. $5 \mathrm{~b}$ is also a function of the wavelength; thus the uncertainty due to Lambertian assumption is dependent on spectral extinction of an aerosol model.

Figure 6 shows calculations of diurnal aerosol radiative efficiency at the top and bottom of atmosphere for Lambertian and BRDF surface reflectance for different types of aerosol and surface. Several observations can be done from this figure. First, diurnal radiative efficiencies can be intercompared for key aerosol types over different surfaces. It can be observed, for example, that over a bright desert surface, biomass burning and mixed aerosol type produce mostly positive instantaneous radiative effects at TOA (Fig. 6c, g, i). A mixture of dust and biomass burning over a Sahel type surface (Fig. $6 \mathrm{~g}$ ) produces a positive instantaneous radiative effect when SZA is less than $53^{\circ}(\cos (\mathrm{SZA})>0.6)$. Note that during the biomass burning season in the Sahel region (January-February) the minimal SZA is in range of about 16 to $37^{\circ}$. It is also remarkable that relatively weak absorbing dust may still produce positive instantaneous radiative effect at TOA over bright desert (Fig. 6a) if the SZA is less than 45 or $37^{\circ}(\cos (\mathrm{SZA})>0.7$ or 0.8$)$, while absorbing biomass burning aerosol over a southern African surface always produce a negative radiative effect (Fig. 6c). With respect to the surface model assumption, Fig. 6 shows an important influence of Lambertian vs. BRDF-based albedo on instantaneous radiative effect, which can even change the sign from negative to positive. The results of calculations therefore make evident that the daily average radiative effect for a given location, which is obtained by integration over a relevant range of SZAs, can also be significantly affected by the assumed surface reflectance model. 


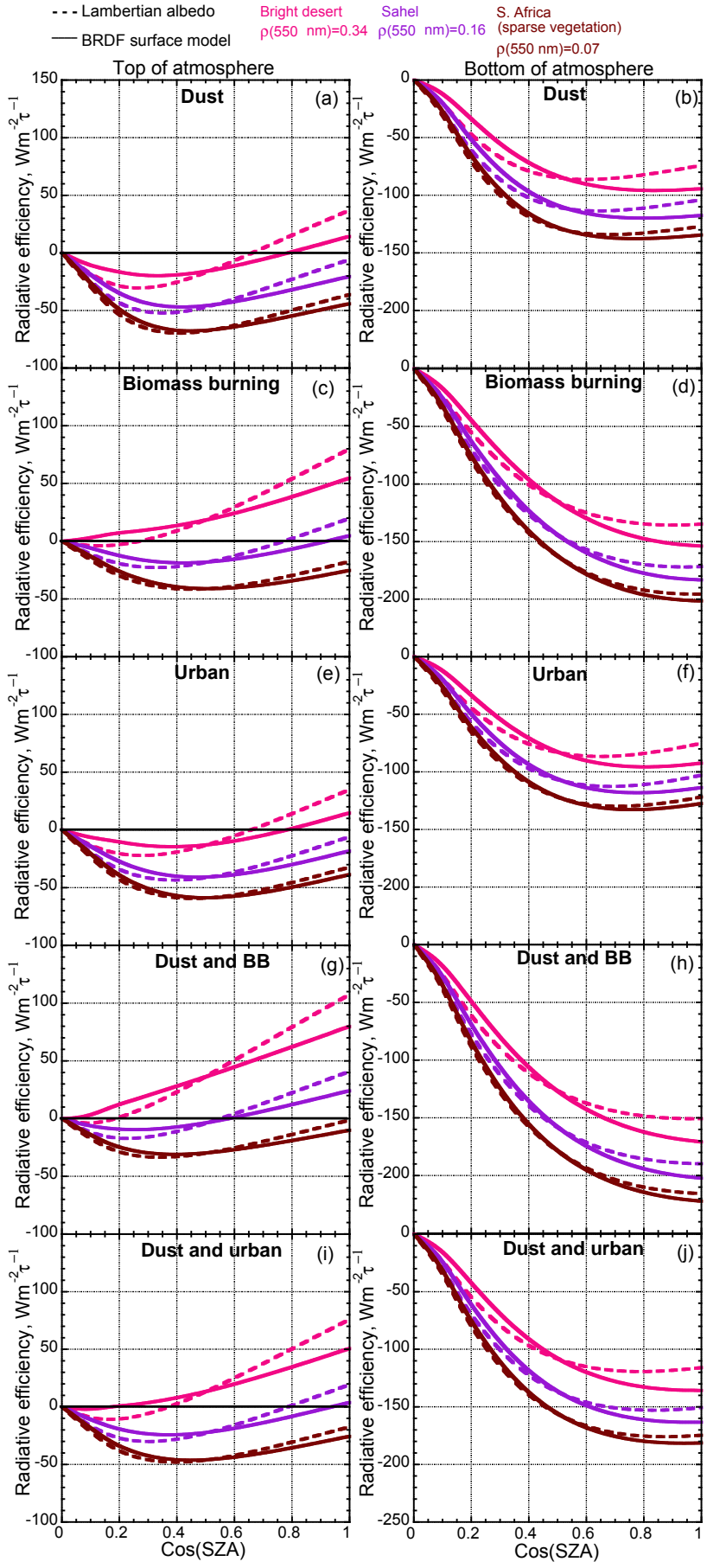

Figure 6. Instantaneous radiative efficiencies calculated using Lambertian and BRDF surface reflectance calculated for five employed aerosol models and three surface types.

Figure 7 shows the daily average values of aerosol radiative efficiency for the same scenarios as in Fig. 6. The daily average values are calculated here for the daylight fraction of 0.5 and for the minimal SZA of $0^{\circ}$. Similarly to Fig. 6, the daily average aerosol radiative efficiency is presented for the aerosol models as a function of surface brightness. In addition, it evaluates the influence of the Lambertian vs. BRDF surface reflectance. For instance, Fig. 7a shows that the daily average radiative efficiency of biomass burning and both mixed aerosol models switches sign at TOA when surface albedo is brighter than about 0.15 or 0.2 at $550 \mathrm{~nm}$; the daily values of dust and urban aerosol stay negative for the presented range of surface albedos. The ratio of aerosol radiative efficiencies over Lambertian to BRDF-based albedo as a function of surface brightness (Fig. 7c) shows the percentage of the uncertainty due to the Lambertian surface assumption. When the radiative effect is negative, the ratio below unity means that the daily average cooling effect is underestimated; when the radiative effect is positive, the ratio above unity means overestimation of the warming effect. At the TOA, the calculated uncertainty ranges up to $30 \%$, depending on aerosol model and surface brightness. It is also evident that the magnitude of the positive radiative effect contribution is dependent on minimal SZA. Therefore, as follows from Fig. 6, for low sun elevation (high latitudes or winter season) the Lambertian surface assumption can also cause a systematic overestimation of aerosol cooling in instantaneous and daily radiative effect values. However, if we consider possible small differences between Lambertian and BRDF-based albedos for vegetation surfaces, which are frequent at high latitudes, the effect in this case can be diminished. At the BOA, influence of the surface model is less important, however, is still distinct for the instantaneous values (Fig. 6).

\section{Particles sphericity assumption in radiative effect calculation}

\subsection{Evaluation of uncertainty}

Phase function of spheres is known to differ from that of randomly oriented spheroidal particles used for modeling optical properties of nonspherical aerosol. Since spheres generally scatter stronger than spheroids at backward scattering angles, it could be expected that the upward hemispherical solar flux is also stronger for spheres. However, this difference is not evident without conducting a rigorous calculation. First of all, not at every scattering angle is the directional scattering of spheres superior of spheroids. For example, for the dust aerosol model, scattering by spheroids dominates between $\sim 90$ and $\sim 140^{\circ}$ (Fig. 8a). Therefore, for low sun elevations, scattering at these angles will contribute more strongly to the total upward flux. This also implies that the effect of nonspherical-spherical differences on upward flux depends on SZA. Second, it is known that the phase function is changing spectrally; thus it is possible that the nonspherical-spherical difference is also spectrally dependent and contributes differently over the solar spectrum. Now, supposing that the AOT is known, we would like to 

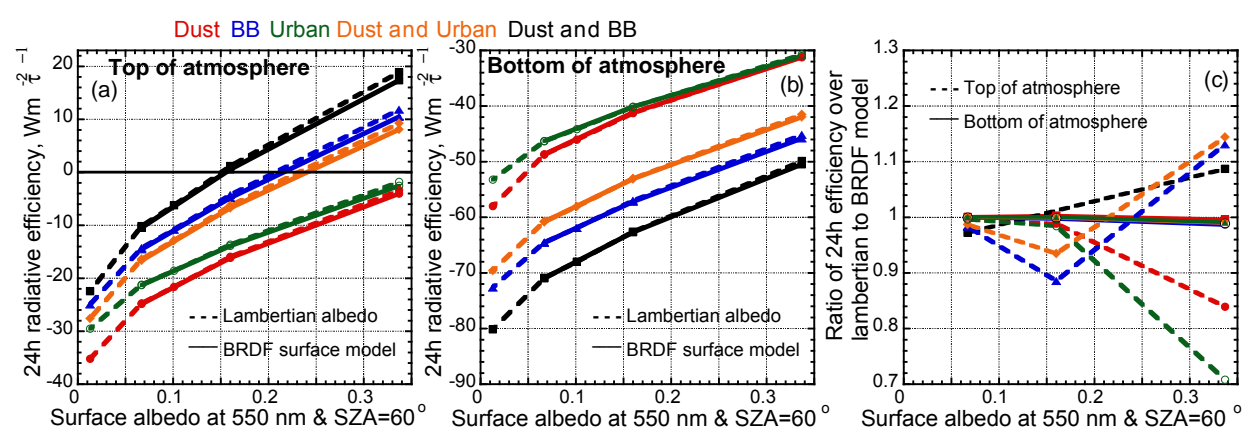

Figure 7. Daily average aerosol radiative efficiencies at the (a) top and (b) bottom of atmosphere calculated using Lambertian and BRDF surface reflectance. The values are presented as a function of surface albedo at $550 \mathrm{~nm}$ and solar zenith angle of $60^{\circ}$. Panel (c) presents ratio of daily radiative effects calculated with Lambertian and BRDF surface models. Notes: (i) mixture of dust and biomass burning is presented only by two points because small variability of values around 0 gives large relative difference for the intermediate surface albedo; (ii) for the ocean surface albedo $(0.013$ at $550 \mathrm{~nm})$ calculations are done for the Lambertian model only.
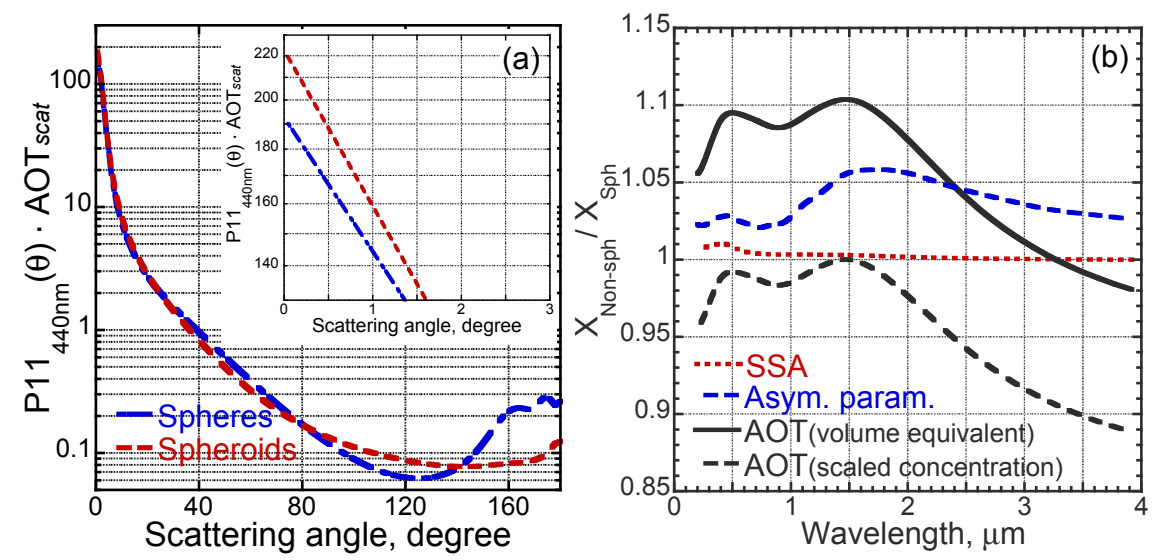

Figure 8. (a) Phase function at $440 \mathrm{~nm}$ of dust aerosol model calculated using ensemble of randomly oriented volume-equivalent spheroidal and spherical particles. (b) Ratios of aerosol optical thickness, single scattering albedo and asymmetry parameter calculated using volumeequivalent nonspherical ( $\left.X_{\text {non-sph }}\right)$ and spherical $\left(X_{\text {sph }}\right)$ particles (dashed line AOT is the ratio using spheres with scaled number concentration in a way that gives the same maximal AOT as the spheroid; solid line AOT is the ratio without scaling).

evaluate uncertainty in the aerosol radiative effect due to differences in angular redistribution of scattering by volumeequivalent spheres and spheroids. The volume equivalence is often used because atmospheric aerosol particles are mainly smaller than the wavelength and in this regime their scattering and absorption properties primary depend on the volume. However, while using volume-equivalent spherical and spheroidal particles, one has to be aware that the extinction cross section is also expected to change. This is because the randomly oriented spheroid has larger geometrical cross section than the volume-equivalent sphere. In fact, the theorem of Cauchy establishes that the average shadow area of a convex body equals one-quarter the surface area of the body, while the geometry prescribes that the surface area of spheroid is always larger than of volume-equivalent sphere. Thus, the shadow area or the geometrical cross section of spheroids is always larger, which may signifies increase of the extinction cross section as well. In fact, the nonspherical- spherical extinction ratio in Fig. 8b (black solid line) is generally above the unity. Nevertheless, in a recent work by Kostinski and Mongkolsittisilp (2013) (see Sect. 3, Fig. 4) it is discussed that due to resonances in some size parameter regimes, extinction of spheroids can be smaller than that of volume-equivalent spheres. Of course, having realistic particle size distribution instead of a single particle can smooth the effect of resonances, but computations show that the phenomena exist for a realistic size distribution of dust that is employed in this study, i.e., the ratio of extinctions gets below unity for long wavelengths (see black solid line in Fig. 8b). Additionally, even when above the unity, the extinctions ratio is waving spectrally, reflecting a different contribution of the resonances as a function of size parameter. More on this subject will be elaborated in further studies (A. Kostinski and Y. Derimian, personal communication, 2014). However, considering that only the phase function assumption is questioned in our work, the effect of different cross sections 
should be excluded and the AOT kept identical, which appears to not be evident when volume and not surface area equivalency is employed. To achieve equality of the AOT in our calculations we attempt to scale the aerosol number concentration in a way that it will give quasi-similar AOT values. Although the identical AOTs can be achieved only at some wavelengths, fitting the AOTs at the wavelength of maximum intensity of the solar radiation or at the peak of the extinction ratio can minimize the effect of varying cross section. The dashed black line in Fig. 8b shows the extinction ratio after the scaling, done in such a way that it is equal to unity at the peak of the ratio. In this case the extinction of spheres is only $\sim 1-2 \%$ larger than that of spheroids in the part of the solar spectrum containing most of the energy. Despite that, the difference becomes large in the spectrum beyond $\sim 2 \mu \mathrm{m}$ and below $\sim 0.3 \mu \mathrm{m}$. At the same time, the gaseous absorption in this spectral region becomes important - it minimizes the influence of the difference in the AOTs. Increase of the averaged projected area of volume-equivalent spheroids also results in a stronger forward peak of the directional scattering (see inset in Fig. 8a). This indeed contributes to an increase in the asymmetry parameter of the nonspherical relative to spherical particles model (see the asymmetry parameter ratio of nonspherical to spherical model in Fig. 8b). Also, the ratio of the asymmetry parameters is waving spectrally, indicating spectral dependence in nonspherical-spherical difference of the directional scattering; however, it is persistently superior of unity. Lower asymmetry of forward to backward scattering of spheres corresponds to a stronger contribution of the backward scattering fraction that hints of a stronger cooling effect (backward to space scattering). As for the single scattering albedo (red dashed line in Fig. 8b), although a small variation appears at short wavelengths of the solar spectrum, it is within only $1 \%$ underestimation when the spherical model is used instead of spheroids. This result is also in line with previous studies (Mishchenko et al., 1997; Dubovik et al., 2006). It is worthwhile to note, however, that a recent study by Legrand et al. (2014) shows that in the thermal infrared, where absorption constitutes the dominant part of the extinction, the shape of particles has a notable effect on the absorption.

In order to evaluate uncertainties in aerosol radiative effect due to assumption on spherical particles we calculate instantaneous radiative effect for nonspherical and spherical dust aerosol models. The calculations are conducted using detailed phase function or asymmetry parameter and over different types of the underlying surface. The results show that, while employing the detailed phase function (Fig. 9a, b), the spherical aerosol model leads to overestimation of cooling at TOA and BOA over dark surfaces; the relative differences in the instantaneous values range between $\sim 1$ and $9.5 \%$ and depend on the SZA (Fig. 9c, d). The exact calculations therefore confirm the above-discussed hypothesis of overestimation of the cooling effect. At the same time, neglecting nonsphericity can also cause some overes-
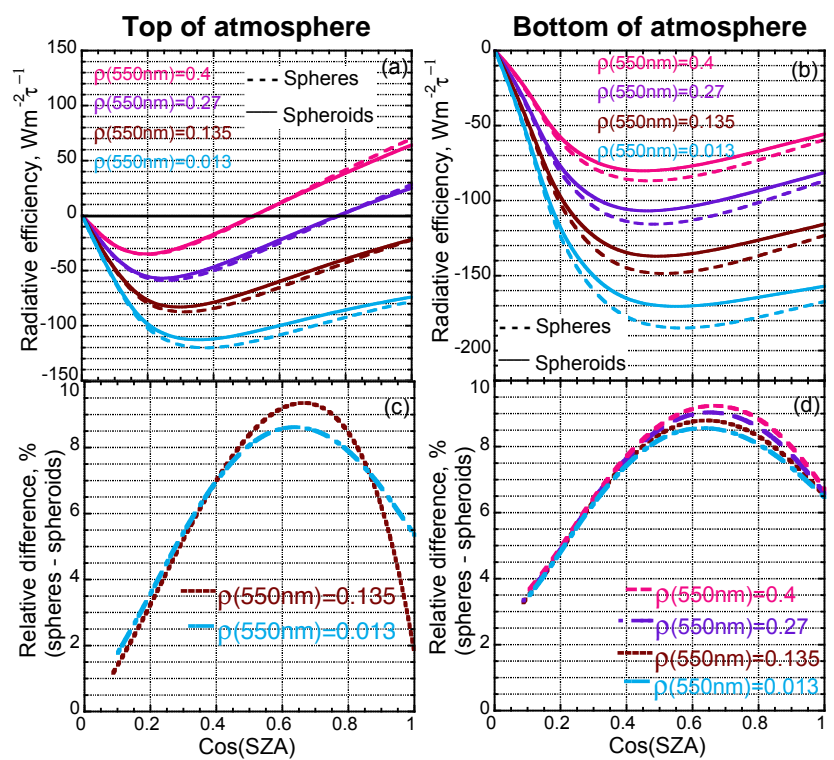

Figure 9. Nonspherical-spherical differences in radiative efficiencies at the top and bottom of atmosphere using detailed phase function of a dust aerosol model. Calculations are done for different surface reflectance using a Lambertian model. Panels (a) and (b) present instantaneous radiative efficiencies for nonspherical and spherical cases; panels (c) and (d) present relative differences over dark surfaces. The relative difference curves for high surface albedo may have very large values because small uncertainties for nearzero radiative efficiencies result in relative differences of $\sim 80$ $90 \%$ (not shown).

timation of the warming effect at TOA (Fig. 9a). This may happen over bright surfaces for high sun elevation when surface reflectance overcomes a critical value with respect to $\omega_{0}$ (Fraser and Kaufman, 1985) and aerosol radiative effect becomes positive. The calculations show that instantaneous radiative efficiencies at maximal sun elevation can reach an overestimation of warming by up to $12 \%$. In the daily average radiative efficiencies, computed assuming maximal sun elevation $\left(\mathrm{SZA}=0^{\circ}\right)$ and daylight fraction of 0.5 , overestimation of cooling, however, still dominates; the differences range between 2.5 and $6 \%$ at TOA and $\sim 6$ and $7 \%$ at BOA (Fig. 10a, b). Based on the analysis of the differences in instantaneous values, it is evident that differences in the daily average values also depend on the surface brightness; it can be seen that the differences decrease as the surface brightness increases. In addition, the errors are expected be influenced by multiple scattering effects that may smooth the nonspherical-spherical differences in the directional scattering. To evaluate the order of the multiple scattering influence, the differences were calculated for AOT $(550 \mathrm{~nm})$ of 0.5 and 2.0 (see Fig. 10). It shows that for $4 \times$ increase in AOT, the error in daily average values decrease by about 15 to $20 \%$ at BOA and about 30 to $40 \%$ at TOA; the decrease is roughly doubled for outgoing TOA radiation that was first transmitted and then reflected by the atmosphere. 


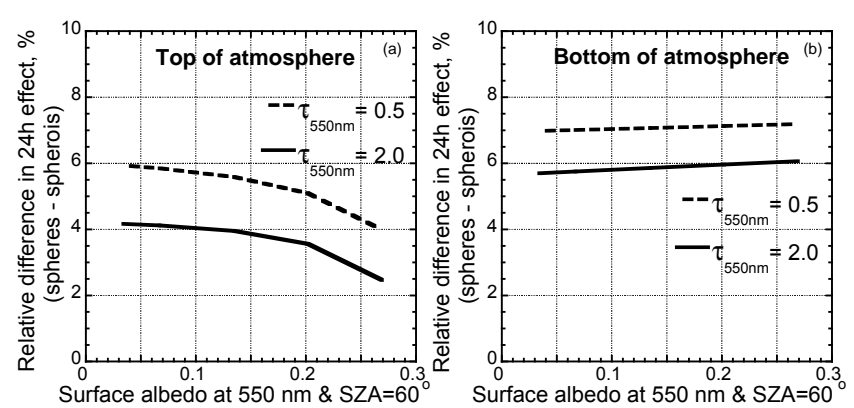

Figure 10. Relative differences in daily average aerosol radiative effect at the (a) top and (b) bottom of atmosphere due to neglecting nonsphericity as a function of surface albedo at $550 \mathrm{~nm}$ and solar zenith angle of $60^{\circ}$. The dashed and solid lines correspond to calculations with aerosol optical thickness at $550 \mathrm{~nm}$ of 0.5 and 2.0, respectively.

It should be mentioned, by consistently using the Mie calculation for the nonspherical aerosol retrievals and flux simulations, it is possible to achieve some reduction of the errors due to the nonspherical-spherical difference in aerosol scattering, as often expected when spherical aerosol model is used in remote sensing retrievals. Nonetheless, these differences cannot be fully eliminated and remain considerable, as shown in Derimian et al. (2008).

\subsection{Nonspherical-spherical difference over Lambertian vs. BRDF surface model}

Another aspect for the analysis is the effect of surface reflectance anisotropy on the manifestation of particle nonsphericity in aerosol radiative effect. The question is how usage of BRDF-based surface reflectance model affects estimation of the nonspherical-spherical errors in aerosol radiative effect? In order to answer this question we re-calculated the nonspherical-spherical errors using BRDF surface models. The results show that depending on the SZA the calculated errors are partially reduced or increased. The errors variability also depends on the surface type. However, overall, the differences stay within a similar range to the Lambertian surface model. The conclusion is valid for the instantaneous (Fig. 11) and, as a consequence, for the daily average values (not shown here).

\section{Employment of detailed phase function vs. asymmetry parameter}

A comparison was conducted between calculations of radiative effect using simplified representation of aerosol directional scattering, i.e., accounting only for asymmetry parameter, and using accurate calculations with detailed phase function. In this analysis two main questions were posed. How large is the error in calculated radiative effect if only asymmetry of phase function was accounted for? Also, what
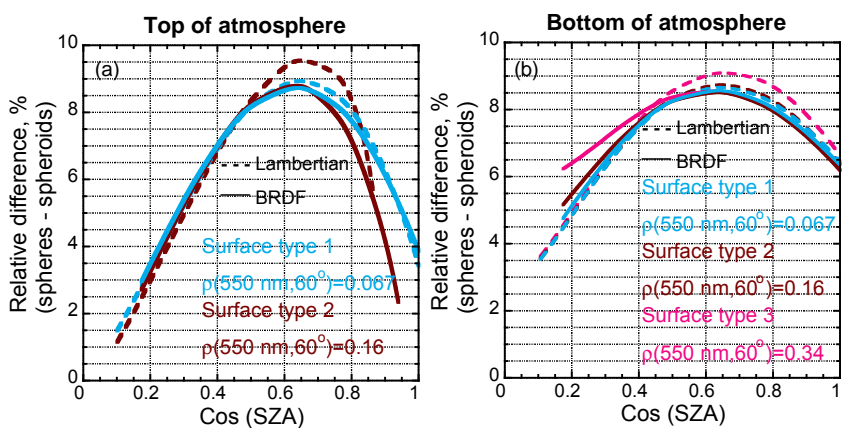

Figure 11. Relative differences in instantaneous radiative efficiencies due to aerosol sphericity assumption at the (a) top and (b) bottom of atmosphere calculated for Lambertian and BRDF surface reflectance models and for different surface types.

kind of uncertainly can be expected for the nonspherical aerosol if this simplification is used in the calculation of radiative effects? To seek the answers we compared the calculation using only asymmetry parameter with accurate calculations where the phase function features were accounted using a 12-moment expansion of the Legendre polynomial. Figure 12 presents the calculated diurnal radiative efficiencies of dust aerosol model over Lambertian surface using only the asymmetry parameter. From a comparison with Fig. 9a and b showing the same, using the detailed phase function, we can notice a significant change in the shape of diurnal dependence of aerosol radiative efficiency at TOA as well as at BOA. That is, the radiative efficiency varies much stronger with SZA when the details of the directional scattering are neglected. At the SZA of $\sim 60^{\circ}(\cos (\mathrm{SZA})$ of $0.4-0.5)$ the cooling effect appears to be systematically overestimated; however, at small SZAs $(\cos (\mathrm{SZA}) \approx 1)$ the cooling is underestimated at the top and bottom of atmosphere. When the values are positive at the top of atmosphere, the warming is overestimated. Figure 12 presents the results for the nonspherical dust aerosol model, but substitution by the asymmetry parameter yields a similar effect for all other aerosol models considered in this study. It has to be mentioned that when only the asymmetry parameter is used, it can be expected that most of the errors in radiative effect calculations are nearly canceled for daily-integrated values. However, this cancelation happens only if the sun reaches small SZAs. Evidently this is not the case for high latitudes or the winter season. Therefore it can be concluded that in daily-average values usage of the asymmetry parameter may produce an overestimation of the aerosol cooling effect, while the magnitude of this overestimation depends on latitude and season. With respect to the errors in radiative effect of the nonspherical aerosol, the usage of only the asymmetry parameter yields a significant change in dependence of the error on SZA. Both at TOA and BOA, the error increases exponentially, reaching a maximum at SZA of $0^{\circ}$ (see Fig. 12c, d). In the daily average values, however, the errors are somewhat lower than in 

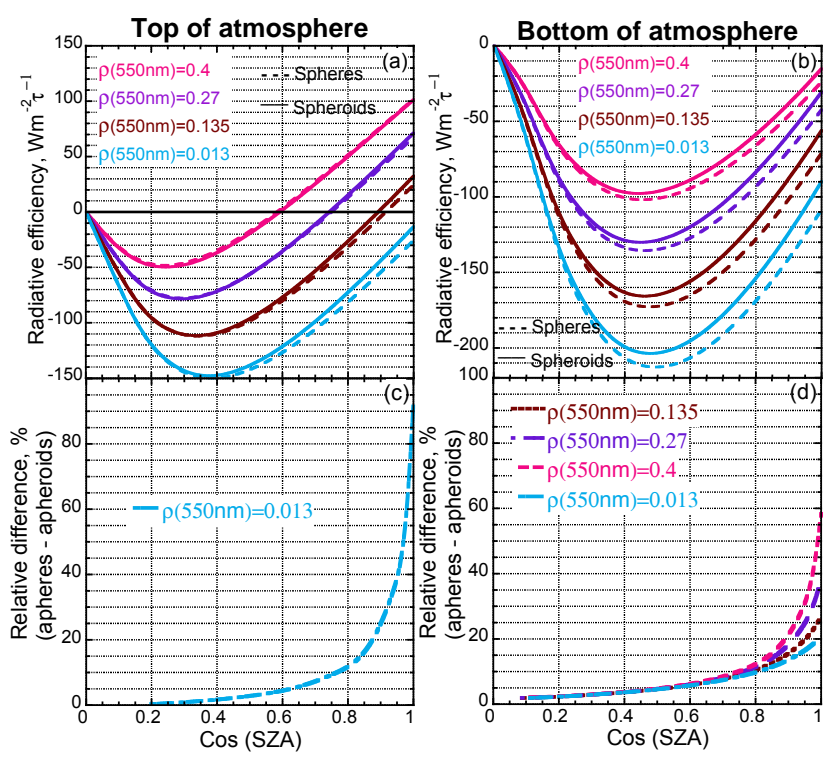

Figure 12. Same as in Fig. 9 but using calculations of only the asymmetry parameter of the phase function. Note that the relative differences in instantaneous radiative efficiencies at the top of atmosphere (panel c) are presented only for the dark surface case. For the high surface albedo the differences appear to have an opposite sign and be large because small uncertainties in the values of radiative efficiencies around 0 produce large relative errors (up to $\sim 200 \%$ ).

the case of detailed phase function because of compensation of high errors at small SZAs by very low errors at SZA $>60^{\circ}$.

\section{Illustration of radiative effect calculations over Africa}

In this section we illustrate feasibility of rigorous direct aerosol radiative effect calculations on a large scale using satellite observations. It is done as part of the GRASP algorithm application for POLDER/PARASOL observations. The product is of particular interest because it provides detailed aerosol characteristics, including absorption, also over bright surfaces where information about aerosol properties is rarely available. With a goal to test the computational tool and assess an observation-based aerosol radiative effect and its spatial variability, the calculations were conducted for POLDER/PARASOL observations during summer 2008 (June, July, August) over a part of Africa known as one of the major sources of the desert dust. It has to be noted, however, that the GRASP algorithm is still in its completion phase and that the quality of the aerosol properties retrievals is in a validation process. In this work we therefore present an intercomparison of AOT and $\omega_{0}$ retrieved by GRASP from POLDER/PARASOL and that from the conventional AERONET product. The intercomparison is conducted using four AERONET sites with good statistic of observations and located in the area of interest (Banizoum-
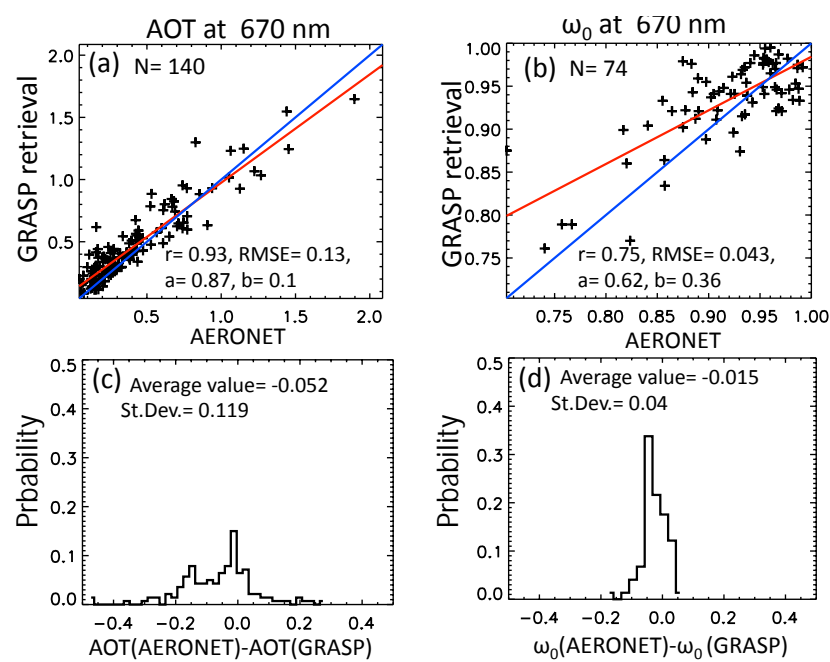

Figure 13. Intercomparison between GRASP retrievals applied for POLDER/PARASOL observations and operational AERONET product during 2008 for ensemble of observations at four sites (Banizoumbou, Agoufou, IER Cinzana and DMN Maine Soroa). Panels (a) and (b) present correlations between AOT and $\omega_{0}$ at $670 \mathrm{~nm}$, respectively; (c, d) probability distributions of absolute differences for AOT and $\omega_{0}$. The temporal threshold is $15 \mathrm{~min}$ between PARASOL and AERONET observations; the products from the groundbased measurements are compared to those from the space-borne measurements of about $6 \times 6 \mathrm{~km}$ pixel, which includes the site.

bou, Agoufou, IER Cinzana and DMN Maine Soroa sites). In order to increase the statistics of joint PARASOL and AERONET observations and to cover various aerosol types and surface reflectance, 1 year (2008) of data was analyzed. Of course, the intercomparison at the selected sites is not fully representative for the entire area. Uncertainties can appear for cases of very low AOT, in regions with complex landscape (mountains, mixed land/water pixels) and failures of the cloud mask. Nevertheless, the conducted intercomparison shows very encouraging correlation coefficients and small uncertainties (root mean square error and standard deviation from AERONET) both for AOT and $\omega_{0}$ (see Fig. 13). The results are obtained for \pm 15 min temporal matching criteria between PARASOL and observations and for PARASOL pixels (with about $6 \times 6 \mathrm{~km}$ spatial resolution) resolution) collocated to each of the selected AERONET stations. In addition to comparisons with AERONET, analysis of the residuals of the fit for the ensemble of the retrievals employed in this work did not indicate any major problem.

Figure 14 presents the means for 3 months of (i) daily average top- and bottom-of-atmosphere net aerosol radiative effects, (ii) radiative efficiencies calculated with respect to AOT at $550 \mathrm{~nm}$ (interpolated from nominal wavelength of POLDER), (iii) AOT at $565 \mathrm{~nm}$, (iv) underlying surface albedo at $565 \mathrm{~nm}$ and (v) spectral $\omega_{0}$ (presented by means of two wavelengths, 443 and $1020 \mathrm{~nm}$ ). The domain averages and standard deviations of the characteristics presented in 



Figure 14. Three-month (JJA 2008) means of (a) top- and (b) bottom-of-atmosphere (TOA and BOA) $24 \mathrm{~h}$ average net aerosol radiative effect, (c, d) the corresponding radiative efficiencies (see Sect. 8 for the interpretation), (e) AOT at $565 \mathrm{~nm}$, (f) underlying surface albedo at $565 \mathrm{~nm}$ and $(\mathrm{g}) \omega_{0}$ at $443 \mathrm{~nm}$ and (h) at $1020 \mathrm{~nm}$ as retrieved and calculated by GRASP algorithm applied to POLDER/PARASOL observations. The panels also include the domain averages and corresponding standard deviations.

Fig. 14 are also indicated in the panels. The domain averages and standard deviations are calculated for all observations during 3 months of summer 2008. As shown in Fig. 14, fine spatial features of aerosol radiative effect (at the top of atmosphere in particular) can be revealed by high spatial resolution of POLDER/PARASOL. A significant amount of pixels, mostly in the northern part of Africa (e.g., central Egypt and northern part of Western Sahara), shows quite strong (up to about 10 to $20 \mathrm{~W} \mathrm{~m}^{-2}$ ) positive radiative effect with the corresponding radiative efficiency over $40 \mathrm{~W} \mathrm{~m}^{-2} \tau^{-1}$ (Fig. 14c, d), despite the fact that the climatological aerosol and surface models in Fig. 7 show positive radiative efficiencies of 
only up to $20 \mathrm{~W} \mathrm{~m}^{-2} \tau^{-1}$. The relatively large positive radiative effect is due to two main factors. First, it happens when the surface reflectance is higher (around 0.4 at $565 \mathrm{~nm}$ ) and the spectral $\omega_{0}$ is lower (around 0.8) compared to the limits assumed in calculations presented in Fig. 7. Evidently, the climatological aerosol and surface models represent only an average but cannot be inclusive of all possible variations of the properties. Second, more important is the nonlinearity of the aerosol radiative effect as function of AOT. In fact, the AOT varies significantly in the real data (Fig. 14e) and strong radiative efficiencies (Fig. 14c) appear when the AOT is low, while the AOT at $550 \mathrm{~nm}$ was set to 1 in calculations of radiative efficiency presented in Fig. 7. In an attempt to illustrate and evaluate the aforementioned reasons, the aerosol models presented in Sect. 3 have been slightly modified and some supplementary calculations have been conducted. For example, the mixture of dust and biomass burning aerosol model has been assumed to be slightly more absorbing by changing the spectral imaginary part of refractive indices $k$ at $440 / 670 / 870 / 1020 \mathrm{~nm}$ from $0.021 / 0.016 / 0.013 / 0.013$ to $0.025 / 0.016 / 0.016 / 0.016$. This modification produces aerosol properties close to those retrieved for central Egypt with the spectral $\omega_{0}(440 / 670 / 870 / 1020 \mathrm{~nm})$ of $0.80 / 0.81 / 0.81 / 0.81$. Radiative effect and efficiency calculated for this aerosol model and for corresponding central Egypt surface albedo of $\sim 0.4$ at $550 \mathrm{~nm}$ are presented in Fig. 15 (labeled as "absorbing mixture"). Modification of the climatological dust aerosol model by increasing $k(440 / 670 / 870 / 1020 \mathrm{~nm})$ from $0.004 / 0.002 / 0.002 / 0.002$ to $0.008 / 0.006 / 0.006 / 0.006$ produces aerosol properties similar to those retrieved for northern part of Western Sahara with spectral $\omega_{0}$ of 0.85/0.89/0.91/0.92, for example. Results of calculations for this aerosol model and for corresponding surface albedo of $\sim 0.35$ at $550 \mathrm{~nm}$ are labeled in Fig. 15 as "absorbing dust". The radiative effect calculations presented in Fig. 15 show first of all that strongly absorbing aerosols over very bright surface produce significant positive radiative effect at the top of atmosphere and reproduce a range of the radiative effect values obtained over central Egypt and Western Sahara. Second, Fig. 15 illustrates that because nonlinearity of the radiative effect is a function of AOT, the values of the radiative efficiency are strongly dependent on the AOT with which they were calculated. The presented example shows variability in radiative efficiency up to $40 \%$ at the top and $25 \%$ at the bottom of atmosphere due to AOT ranging from 0.2 to 1 . This fact implies that one should interpret the maps of radiative efficiency in Fig. 14c and d with caution due to the spatial variation of aerosol concentration.

Noteworthy is also the obtained spectral $\omega_{0}$ (Fig. 14g, h). Although it is generally consistent with $\omega_{0}$ of mineral dust (stronger absorption at $443 \mathrm{~nm}$ than at $1020 \mathrm{~nm}$ ), in some cases the $\omega_{0}$ appears quite low (about 0.8 ) at 443 and $1020 \mathrm{~nm}$, which indicates the presence of probably carbonaceous particles or mixed aerosol (e.g., over central Egypt). For the daily average BOA radiative effect (Fig. 14b) the val-
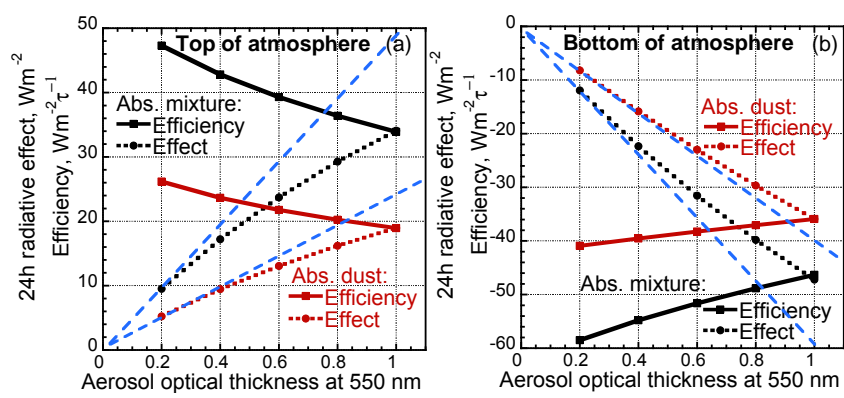

Figure 15. (dashed lines) Dependence between calculated $24 \mathrm{~h}$ average aerosol radiative effect and AOT at $550 \mathrm{~nm}$; (solid lines) $24 \mathrm{~h}$ average aerosol radiative efficiency calculated using AOT presented on the abscissa. Black and red lines correspond, respectively, to "absorbing mixture" and "absorbing dust" aerosol models described in Sect. 8; surface albedo at $550 \mathrm{~nm}$ is set to 0.43 for "absorbing mixture" and 0.34 for "absorbing dust" scenarios; blue lines represent linear dependence between $24 \mathrm{~h}$ average aerosol radiative effect and AOT. Panel (a) is for the top of atmosphere and panel (b) for the bottom of atmosphere.

ues show quite important spatial variability and areas with strong cooling (about $-60 \mathrm{~W} \mathrm{~m}^{-2}$ ) that generally correspond to high AOT. Overall, it can be concluded that the values obtained from POLDER/PARASOL observations are in the range of what could be expected from the theoretical climatological calculations presented in this study. The preliminary results and spatial patterns of the aerosol radiative effect thus demonstrate potential of this highly advanced product of new GRASP algorithm.

\section{Conclusions}

A rigorous yet fast computational tool for calculations of broadband solar flux and aerosol direct radiative effect was presented. The initial version of the tool developed for using AERONET results and employed in the AERONET operational code was significantly revised and integrated into the GRASP (Generalized Retrieval of Aerosol and Surface Properties) algorithm. Therefore, the GRASP retrieval product can include the estimations of radiative effect for interested users. The tool can also be used in research mode for various types of sensitivity analyses.

Using this tool we analyzed sensitivities of the diurnal and daily average shortwave aerosol radiative effects to the details in aerosol and underlying surface characteristics. Overall, the obtained results showed the importance of accurately accounting for details in variability of atmospheric aerosol characteristics, such as AOT, $\omega_{0}$ and $g$ (or phase function), over the solar spectrum in simulations of broadband solar flux and aerosol radiative effect on climate. Diurnal aerosol radiative effect was found as particularly influenced by directional properties of aerosol scattering and by anisotropy of underlying surface reflectance. In fact, not only magni- 
tude but also dependence on the SZA of instantaneous radiative effect is changing for different aerosol models due to differences in aerosol directional scattering. For example, the changes in the directional scattering due to nonsphericity of particles are notably manifested in the dependence of dust aerosol instantaneous radiative effect on SZA. Neglecting nonsphericity of desert dust in the calculation of radiative effect leads to systematic errors. The computations reveal that simplification of details in directional properties of aerosol scattering and reflectance of underlying surface also cause systematic biases, rather than uncertainties, in evaluation of aerosol radiative effect on climate. Namely, the considered here simplifications are (i) accounting for the asymmetry parameter only instead of detailed phase function, (ii) neglecting of phase function features for nonspherical aerosol particles and (iii) directional isotropy of surface reflectance with respect to SZA. We found that using only asymmetry between forward and backward aerosol scattering affects quite significantly the dependence of instantaneous aerosol radiative effect on SZA, relative to usage of the detailed phase function. It tends to overestimate the cooling effect at SZAs around $60^{\circ}$ but underestimate for sun near the zenith. The errors in the daily average values, therefore, depend on latitude and season and are minimized for low latitudes and during the summer. If only asymmetry of phase function was used, the change in diurnal dependence of instantaneous radiative effect was observed for dust and other aerosol types. Utilization of only the asymmetry parameter also significantly affects evaluation of error in radiative forcing due to neglecting of aerosol nonsphericity; the errors in instantaneous values can vary from a few percent to up to $\sim 100 \%$. It should be noted, though, that errors in daily average values are much lower. However, once a detailed phase function is used, the observed error due to neglecting particle nonsphericity is only up to $\sim 10 \%$ in instantaneous and daily average aerosol radiative effect. Because of the dependence of this error on the SZA, the biases are expected to vary as a function of latitude and season, having a tendency of stronger overestimation of cooling for higher latitudes and wintertime.

We emphasize also that a proper intercomparison of radiative effects of volume-equivalent spherical and spheroidal aerosol particles models should account for alteration of geometrical cross section together with directional redistribution of scattering. In our study we apply a scaling of concentration in an attempt to compensate the geometrical and the corresponding extinction cross-section modification. The differences observed in this study between nonspherical and spherical models should be considered a worst-case scenario, but their importance should not be underestimated because they create a notable systematic bias. We also found that using BRDF of surface reflectance instead of Lambertian approximation does not influence significantly the nonsphericalspherical differences, although the diurnal dependence of the error is somewhat modified. The study showed that the nonspherical-spherical difference at the top of atmosphere is also pronouncedly dependent on the magnitude of surface brightness, while at the bottom of atmosphere this dependence practically does not exist. The differences also tend to be reduced with increase in AOT because the multiple scattering effects smooth out differences in the phase functions. It is also important to mention that strong variability of diurnal aerosol radiative effect signifies that the minimal SZA and daylight duration can overcome effects of aerosol type and concentration and thus should be taken into account in intercomparison of daily average aerosol radiative forcing in different time and locations.

Finally, application of rigorous aerosol radiative effect calculations was illustrated as feasible on a large-scale using GRASP algorithm for POLDER/PARASOL observations over Africa. Results of the observation-based calculations present quite a pronounced range of values and spatial variability of the aerosol radiative effect. The obtained values are generally in line with results of calculations for considered here climatological calculations. The effort presents one more step in the measurement-based estimate of the aerosol direct radiative effect on climate.

Acknowledgements. The work is supported by the CaPPA project. The CaPPA project (Chemical and Physical Properties of the Atmosphere) is funded by the French National Research Agency (ANR) through the PIA (Programme d'Investissement d'Avenir) under contract "ANR-11-LABX-0005-01" and by the Regional Council "Nord-Pas de Calais" and the "European Funds for Regional Economic Development" (FEDER). This work was also supported, in part, by the NSF grant AGS-111916.

Edited by: J.-Y. C. Chiu

\section{References}

Andreae, M. O., Jones, C. D., and Cox, P. M.: Strong present-day aerosol cooling implies a hot future, Nature, 435, 1187-1190, 2005.

Bellouin, N., Boucher, O., Vesperini, M., and Tanre, D.: Estimating the direct aerosol radiative perturbation: Impact of ocean surface representation and aerosol non-sphericity, Q. J. Roy. Meteor. Soc., 130, 2217-2232, 2004.

Bellouin, N., Boucher, O., Haywood, J., and Reddy, M. S.: Global estimate of aerosol direct radiative forcing from satellite measurements, Nature, 438, 1138-1141, 2005.

Boucher, O. and Tanré, D.: Estimation of the aerosol perturbation to the Earth's radiative budget over oceans using POLDER satellite aerosol retrievals, Geophys. Res. Lett., 27, 1103-1106, 2000.

Derimian, Y., Leon, J. F., Dubovik, O., Chiapello, I., Tanre, D., Sinyuk, A., Auriol, F., Podvin, T., Brogniez, G., and Holben, B. N.: Radiative properties of aerosol mixture observed during the dry season 2006 over M'Bour, Senegal (African Monsoon Multidisciplinary Analysis campaign), J. Geophys. Res.-Atmos., 113, D00C09, doi:10.1029/2008jd009904, 2008. 
Derimian, Y., Dubovik, O., Tanre, D., Goloub, P., Lapyonok, T., and Mortier, A.: Optical properties and radiative forcing of the Eyjafjallajokull volcanic ash layer observed over Lille, France, in 2010, J. Geophys. Res.-Atmos., 117, D00U25, doi:10.1029/2011jd016815, 2012.

Dubovik, O. and King, M. D.: A flexible inversion algorithm for retrieval of aerosol optical properties from Sun and sky radiance measurements, J. Geophys. Res., 105, 20673-20696, 2000.

Dubovik, O., Holben, B., Eck, T. F., Smirnov, A., Kaufman, Y. J., King, M. D., Tanre, D., and Slutsker, I.: Variability of absorption and optical properties of key aerosol types observed in worldwide locations, J. Atmos. Sci., 59, 590-608, 2002a.

Dubovik, O., Holben, B. N., Lapyonok, T., Sinyuk, A., Mishchenko, M. I., Yang, P., and Slutsker, I.: Non-spherical aerosol retrieval method employing light scattering by spheroids, Geophys. Res. Lett., 29, 1415, doi:1410.1029/2001GL014506, 2002b.

Dubovik, O., Sinyuk, A., Lapyonok, T., Holben, B. N., Mishchenko, M., Yang, P., Eck, T. F., Volten, H., Munoz, O., Veihelmann, B., van der Zande, W. J., Leon, J. F., Sorokin, M., and Slutsker, I.: Application of spheroid models to account for aerosol particle nonsphericity in remote sensing of desert dust, J. Geophys. Res., 111, D11208, doi:10.1029/2005JD006619, 2006.

Dubovik, O., Herman, M., Holdak, A., Lapyonok, T., Tanré, D., Deuzé, J. L., Ducos, F., Sinyuk, A., and Lopatin, A.: Statistically optimized inversion algorithm for enhanced retrieval of aerosol properties from spectral multi-angle polarimetric satellite observations, Atmos. Meas. Tech., 4, 975-1018, doi:10.5194/amt-4975-2011, 2011.

Dubovik, O., Lapyonok, T., Litvinov, P., Herman, M., Fuertes, D., Ducos, F., Lopatin, A., Chaikovsky, A., Torres, B., Derimian, Y., Huang, X., Aspetsberger, M., and Federspiel, C.: GRASP: a versatile algorithm for characterizing the atmosphere, SPIE: Newsroom, doi:10.1117/2.1201408.005558, 2014

Dubuisson, P., Buriez, J. C., and Fouquart, Y.: High spectral resolution solar radiative transfer in absorbing and scattering media: Application to the satellite simulation, J. Quant. Spectrosc. Ra., 55, 103-126, 1996.

Dubuisson, P., Dessailly, D., Vesperini, M., and Frouin, R.: Water vapor retrieval over ocean using near-infrared radiometry, J. Geophys. Res., 109, D19106, doi:10.1029/2004jd004516, 2004.

Dubuisson, P., Roger, J. C., Mallet, M., and Dubovik, O.: A code to compute the direct solar radiative forcing: application to anthropogenic aerosols during the Escompte experiment, Proceedings of IRS 2004: Current Problems in Atmospheric Radiation, 23-28 August 2006, Busan, Korea, 127-130, 2006.

Eck, T. F., Holben, B. N., Reid, J. S., Mukelabai, M. M., Piketh, S. J., Torres, O., Jethva, H. T., Hyer, E. J., Ward, D. E., Dubovik, O., Sinyuk, A., Schafer, J. S., Giles, D. M., Sorokin, M., Smirnov, A., and Slutsker, I.: A seasonal trend of single scattering albedo in southern African biomass-burning particles: Implications for satellite products and estimates of emissions for the world's largest biomass-burning source, J. Geophys. Res.-Atmos., 118, 6414-6432, 2013.

Fraser, R. S. and Kaufman, Y. J.: The Relative Importance of Aerosol Scattering and Absorption in Remote-Sensing, IEEE T. Geosci. Remote, 23, 625-633, 1985.

García, O. E., Díaz, A. M., Expósito, F. J., Díaz, J. P., Dubovik, O., Dubuisson, P., Roger, J. C., Eck, T. F., Sinyuk, A., Derimian, Y., Dutton, E. G., Schafer, J. S., Holben, B. N., and Gar- cia, C. A.: Validation of AERONET estimates of atmospheric solar fluxes and aerosol radiative forcing by ground-based broadband measurements, J. Geophys. Res.-Atmos., 113, D21207, doi:10.1029/2008jd010211, 2008.

García, O. E., Díaz, J. P., Expósito, F. J., Díaz, A. M., Dubovik, O., Derimian, Y., Dubuisson, P., and Roger, J.-C.: Shortwave radiative forcing and efficiency of key aerosol types using AERONET data, Atmos. Chem. Phys., 12, 5129-5145, doi:10.5194/acp-125129-2012, 2012.

Giles, D. M., Holben, B. N., Eck, T. F., Sinyuk, A., Smirnov, A., Slutsker, I., Dickerson, R. R., Thompson, A. M., and Schafer, J. S.: An analysis of AERONET aerosol absorption properties and classifications representative of aerosol source regions, J. Geophys. Res.-Atmos., 117, D17203, doi:10.1029/2012jd018127, 2012.

Hansen, J., Sato, M., Kharecha, P., and von Schuckmann, K. Earth's energy imbalance and implications, Atmos. Chem. Phys., 11, 13421-13449, doi:10.5194/acp-11-13421-2011, 2011.

Haywood, J. M., Pelon, J., Formenti, P., Bharmal, N., Brooks, M., Capes, G., Chazette, P., Chou, C., Christopher, S., Coe, H., Cuesta, J., Derimian, Y., Desboeufs, K., Greed, G., Harrison, M., Heese, B., Highwood, E. J., Johnson, B., Mallet, M., Marticorena, B., Marsham, J., Milton, S., Myhre, G., Osborne, S., Parker, D. J., Rajot, J.-L., Schulz, M., Slingo, A., Tanré, D., and Tulet, P.: Overview of the Dust and Biomass burning Experiment and African Monsoon Multidisciplinary Analysis Special Observational Period-0, J. Geophys. Res.-Atmos., 113, D00C17, doi:10.1029/2008JD010077, 2008.

Kahnert, M. and Kylling, A.: Radiance and flux simulations for mineral dust aerosols: Assessing the error due to using spherical or spheroidal model particles, J. Geophys. Res., 109, D09203, doi:10.1029/2004jd005311, 2004.

Kahnert, M., Nousiainen, T., and Veihelmann, B.: Spherical and spheroidal model particles as an error source in aerosol climate forcing and radiance computations: A case study for feldspar aerosols, J. Geophys. Res., 110, D18S13, doi:10.1029/2004JD005558, 2005.

Kaufman, Y. J., Boucher, O., Tanre, D., Chin, M., Remer, L. A., and Takemura, T.: Aerosol anthropogenic component estimated from satellite data, Geophys. Res. Lett., 32, L17804, doi:10.1029/2005g1023125, 2005.

Kostinski, A. B. and Mongkolsittisilp, A.: Minimum principles in electromagnetic scattering by small aspherical particles, J. Quant. Spectrosc. Ra., 131, 194-201, 2013.

Lacis, A. A. and Oinas, V.: A Description of the Correlated KappaDistribution Method for Modeling Nongray Gaseous Absorption, Thermal Emission, and Multiple-Scattering in Vertically Inhomogeneous Atmospheres, J. Geophys. Res., 96, 9027-9063, 1991.

Legrand, M., Plana-Fattori, A., and N'Doume, C.: Satellite detection of dust using the IR imagery of Meteosat 1. Infrared difference dust index, J. Geophys. Res.-Atmos., 106, 18251-18274, 2001.

Legrand, M., Dubovik, O., Lapyonok, T., and Derimian, Y.: Accounting for particle non-sphericity in modeling of mineral dust radiative properties in the thermal infrared, J. Quant. Spectrosc. Ra., 149, 219-240, 2014.

Lenoble, J., Tanre, D., Deschamps, P. Y., and Herman, M.: A simple method to compute the change in earth atmosphere radiative 
balance due to a stratospheric aerosol layer, J. Atmos. Sci., 39, 2565-2576, 1982.

Lenoble, J., Herman, M., Deuze, J. L., Lafrance, B., Santer, R., and Tanre, D.: A successive order of scattering code for solving the vector equation of transfer in the earth's atmosphere with aerosols, J. Quant. Spectrosc. Ra., 107, 479-507, 2007.

Léon, J.-F., Derimian, Y., Chiapello, I., Tanré, D., Podvin, T., Chatenet, B., Diallo, A., and Deroo, C.: Aerosol vertical distribution and optical properties over M'Bour $\left(16.96^{\circ} \mathrm{W} ; 14.39^{\circ} \mathrm{N}\right)$, Senegal from 2006 to 2008, Atmos. Chem. Phys., 9, 9249-9261, doi:10.5194/acp-9-9249-2009, 2009.

Litvinov, P., Hasekamp, O., and Cairns, B.: Models for surface reflection of radiance and polarized radiance: Comparison with airborne multi-angle photopolarimetric measurements and implications for modeling top-of-atmosphere measurements, Remote Sens. Environ., 115, 781-792, 2011.

Litvinov, P., Hasekamp, O., Dubovik, O., and Cairns, B.: Model for land surface reflectance treatment: Physical derivation, application for bare soil and evaluation on airborne and satellite measurements, J. Quant. Spectrosc. Ra., 113, 2023-2039, 2012.

Lopatin, A., Dubovik, O., Chaikovsky, A., Goloub, P., Lapyonok, T., Tanré, D., and Litvinov, P.: Enhancement of aerosol characterization using synergy of lidar and sun-photometer coincident observations: the GARRLiC algorithm, Atmos. Meas. Tech., 6, 2065-2088, doi:10.5194/amt-6-2065-2013, 2013.

Maignan, F., Breon, F. M., and Lacaze, R.: Bidirectional reflectance of Earth targets: Evaluation of analytical models using a large set of spaceborne measurements with emphasis on the Hot Spot, Remote Sens. Environ., 90, 210-220, 2004.

Markowicz, K. M., Flatau, P. J., Remiszewska, J., Witek, M., Reid, E. A., Reid, J. S., Bucholtz, A., and Holben, B.: Observations and modeling of the surface aerosol radiative forcing during $\mathrm{UAE}(2)$, J. Atmos. Sci., 65, 2877-2891, 2008.

Mishchenko, M. I., Lacis, A. A., Carlson, B. E., and Travis, L. D.: Nonsphericity of dust-like tropospheric aerosols: implications for aerosol remote sensing and climate modeling, Geophys. Res. Lett., 22, 1077-1080, 1995.

Mishchenko, M. I., Travis, L. D., Kahn, R. A., and West, R. A.: Modeling phase functions for dustlike tropospheric aerosols using a shape mixture of randomly oriented polydisperse spheroids, J. Geophys. Res.-Atmos., 102, 16831-16847, 1997.

Nakajima, T. and Tanaka, M.: Algorithms for Radiative Intensity Calculations in Moderately Thick Atmospheres Using a Truncation Approximation, J. Quant. Spectrosc. Ra., 40, 51-69, 1988.

Rahman, H., Verstraete, M. M., and Pinty, B.: Coupled surfaceatmosphere reflectance (CSAR) Model. 1. Model description and inversion on synthetic data, J. Geophys. Res.-Atmos., 98, 20779 20789, 1993.

Remer, L. A. and Kaufman, Y. J.: Aerosol direct radiative effect at the top of the atmosphere over cloud free ocean derived from four years of MODIS data, Atmos. Chem. Phys., 6, 237-253, doi:10.5194/acp-6-237-2006, 2006.

Roger, J. C., Mallet, M., Dubuisson, P., Cachier, H., Vermote, E., Dubovik, O., and Despiau, S.: A synergetic approach for estimating the local direct aerosol forcing: Application to an urban zone during the Experience sur Site pour Contraindre les Modeles de Pollution et de Transport d'Emission (ESCOMPTE) experiment, J. Geophys. Res., 111, D13208, doi:13210.11029/12005JD006361, 2006.
Roujean, J. L., Leroy, M., and Deschamps, P. Y.: A bidirectional reflectance model of the earths surface for the correction of remotesensing data, J. Geophys. Res.-Atmos., 97, 20455-20468, 1992.

Schaepman-Strub, G., Schaepman, M. E., Painter, T. H., Dangel, S., and Martonchik, J. V.: Reflectance quantities in optical remote sensing-definitions and case studies, Remote Sens. Environ., 103, 27-42, 2006.

Sinyuk, A., Dubovik, O., Holben, B., Eck, T. F., Breon, F. M., Martonchik, J., Kahn, R., Diner, D. J., Vermote, E. F., Roger, J. C., Lapyonok, T., and Slutsker, I.: Simultaneous retrieval of aerosol and surface properties from a combination of AERONET and satellite data, Remote Sens. Environ., 107, 90-108, 2007.

Smirnov, A., Holben, B. N., Eck, T. F., Dubovik, O., and Slutsker, I.: Cloud-screening and quality control algorithms for the AERONET database, Remote Sens. Environ., 73, 337-349, 2000.

Stamnes, K., Tsay, S. C., Wiscombe, W., and Jayaweera, K.: Numerically Stable Algorithm for Discrete-Ordinate-Method Radiative-Transfer in Multiple-Scattering and Emitting Layered Media, Appl. Optics, 27, 2502-2509, 1988.

Su, W. Y., Loeb, N. G., Schuster, G. L., Chin, M., and Rose, F. G.: Global all-sky shortwave direct radiative forcing of anthropogenic aerosols from combined satellite observations and GOCART simulations, J. Geophys. Res.-Atmos., 118, 655-669, 2013.

Tanré, D., Bréon, F. M., Deuzé, J. L., Dubovik, O., Ducos, F., François, P., Goloub, P., Herman, M., Lifermann, A., and Waquet, F.: Remote sensing of aerosols by using polarized, directional and spectral measurements within the A-Train: the PARASOL mission, Atmos. Meas. Tech., 4, 1383-1395, doi:10.5194/amt-4-1383-2011, 2011.

Volten, H., Munoz, O., Rol, E., de Haan, J. F., Vassen, W., Hovenier, J. W., Muinonen, K., and Nousiainen, T.: Scattering matrices of mineral aerosol particles at $441.6 \mathrm{~nm}$ and $632.8 \mathrm{~nm}$, J. Geophys. Res., 106, 17375-17401, doi:10.1029/2001jd900068, 2001.

Wanner, W., Li, X., and Strahler, A. H.: On the derivation of kernels for kernel-driven models of bidirectional reflectance, J. Geophys. Res.-Atmos., 100, 21077-21089, doi:10.1029/95jd02371, 1995.

Yi, B. Q., Hsu, C. N., Yang, P., and Tsay, S. C.: Radiative transfer simulation of dust-like aerosols: Uncertainties from particle shape and refractive index, J. Aerosol Sci., 42, 631-644, 2011.

Yu, H., Kaufman, Y. J., Chin, M., Feingold, G., Remer, L. A., Anderson, T. L., Balkanski, Y., Bellouin, N., Boucher, O., Christopher, S., DeCola, P., Kahn, R., Koch, D., Loeb, N., Reddy, M. S., Schulz, M., Takemura, T., and Zhou, M.: A review of measurement-based assessments of the aerosol direct radiative effect and forcing, Atmos. Chem. Phys., 6, 613-666, doi:10.5194/acp-6-613-2006, 2006.

Yu, H. B., Dickinson, R. E., Chin, M., Kaufman, Y. J., Zhou, M., Zhou, L., Tian, Y., Dubovik, O., and Holben, B. N.: Direct radiative effect of aerosols as determined from a combination of MODIS retrievals and GOCART simulations, J. Geophys. Res.Atmos., 109, D03206, doi:10.1029/2003jd003914, 2004.

Zhou, M., Yu, H., Dickinson, R. E., Dubovik, O., and Holben, B. N.: A normalized description of the direct effect of key aerosol types on solar radiation as estimated from Aerosol Robotic Network aerosols and Moderate Resolution Imaging Spectroradiometer albedos, J. Geophys. Res.-Atmos., 110, D19202, doi:10.1029/2005jd005909, 2005. 